\title{
Julija Zepa
}

\section{The Relationship of Candidate Gene Polymorphisms with Ankylosing Spondylitis and its Clinical Course}

Summary of the Doctoral thesis for obtaining a doctoral degree (Ph.D.)

\author{
Sector - Clinical Medicine \\ Sub-sector - Rheumatology
}

Riga, 2020 


\section{RĪGA STRADINŠ
UNIVERSITY}

Julija Zepa

ORCID 0000-0003-3848-797X

\section{The Relationship of Candidate Gene Polymorphisms with Ankylosing Spondylitis and its Clinical Course}

Summary of the Doctoral Thesis for obtaining a doctoral degree (Ph.D.)

Sector - Clinical Medicine

Sub-Sector - Rheumatology

Riga, 2020 
The Doctoral Thesis was developed at Rīga Stradiņš University, Pauls Stradins Clinical University Hospital and Latvian Biomedical Research and Study Centre

Supervisor of the Doctoral Thesis :

Dr. habil. med., Professor Daina Andersone

University of Latvia, Faculty of Medicine

Dr. med., Professor, full member of LAS Aivars Lejnieks

Rīga Stradiņš University, Latvia

Scientific Advisor:

Dr. med., Liene N̦ikitina-Zaķe

Rīga Stradiņš University, Latvia

Official Reviewers:

Dr. med., Professor Valda Staṇēviča

Rīga Stradiņš University, Department of Paediatrics, Latvia

Dr. habil. med., Professor Ingrīda Rumba-Rozenfelde

University of Latvia, Faculty of Medicine

Dr. med., Professor Irena Butrimiene

Vilnius University, Faculty of Medicine, Lithuania

Defense of the Doctoral Thesis will take place at the public session of the Promotion Council of Clinical Medicine on 4 September 2020 at 15.00 in Hippocrates Lecture Theatre, 16 Dzirciema Street, Rīga Stradiņš University.

The Doctoral Thesis is available in RSU Library and on RSU website: https://www.rsu.lv/doctoral theses

Secretary of the Promotion Council:

Dr. med., Associate Professor Viktorija K̦ēniṇa 


\section{Table of contents}

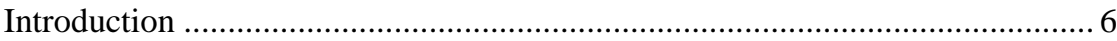

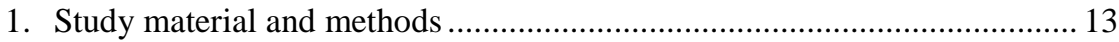

1.1. Included persons, inclusion and exclusion criteria ............................. 13

1.1.1. Demographic characteristics of ankylosing spondylitis patients and control group.................................................................. 14

1.1.2. Biological material used in the study ...................................... 14

1.2. Clinical and radiological investigation methods ................................ 15

1.3. Selected biomarkers of ankylosing spondylitis................................. 17

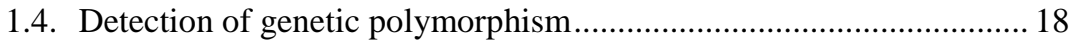

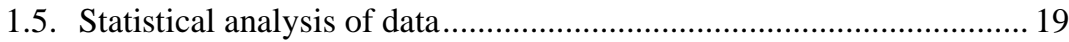

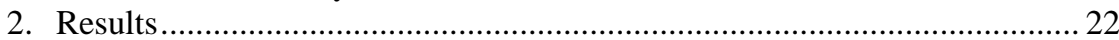

2.1. Characteristics of ankylosing spondylitis patients ............................. 22

2.2. Polymorphisms of the ankylosing spondylitis candidate genes .......... 25

2.3. The link of ankylosing spondylitis candidate gene polymorphisms

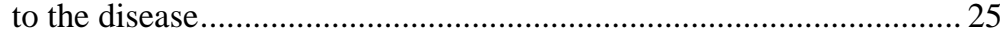

2.4. The link of ankylosing spondylitis candidate gene polymorphisms to the extraspinal manifestations of the disease - uveitis and

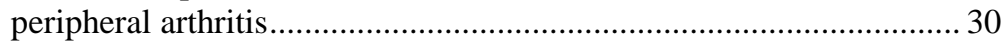

2.5. The link of multilocus haplotypes with ankylosing spondylitis

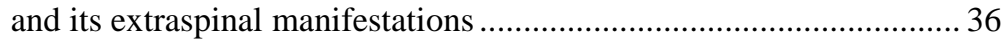

2.5.1. Haplotypes within the single gene ......................................... 37

2.5.2. Haplotypes within the genes coding the proteins of the TNF family signaling pathway ...................................... 39

2.5.3. Haplotypes formed by the SNPs of the genes encoding the signaling pathway of interaction of $\mathrm{TNF} \alpha$, T lymphocytes

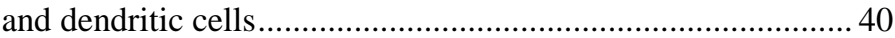

2.5.4. Haplotypes of the linked SNPs ................................................ 43

2.6. The link of the ankylosing spondylitis candidate gene polymorphisms to the disease biomarkers ............................................ 46

2.6.1. The age at the onset of first ankylosing spondylitis

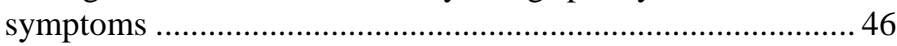

2.6.2. The assessment of spinal structural damage (mSASSS) ......... 47

2.6.3. The relationship and possible impact of the candidate gene polymorphisms of ankylosing spondylitis on the efficacy of the treatment with TNF $\alpha$ inhibitors .......................................... 50

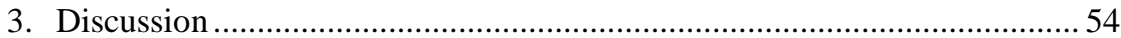

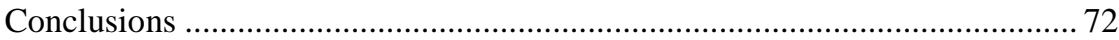

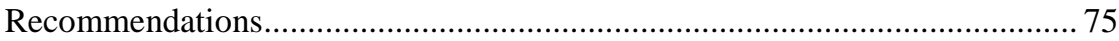

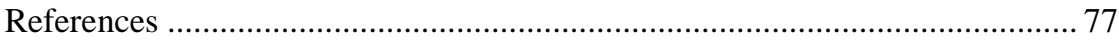

List of published articles and abstracts and participation in congresses and conferences 


\section{Abbreviations}

$\begin{array}{ll}\text { A } & \text { adenine } \\ \text { AS } & \text { ankylosing spondylitis } \\ \text { ASAS } & \text { Assessment of SpondyloArthritis international Society } \\ \text { ASDAS } & \text { Ankylosing Spondylitis Disease Activity Score } \\ \text { BASDAI } & \text { Bath Ankylosing Spondylitis Disease Activity Index } \\ \text { BASFI } & \text { Bath Ankylosing Spondylitis Functional Index } \\ \text { BASMI } & \text { Bath Ankylosing Spondylitis Metrological Index } \\ \text { bDMARD } & \text { biological disease modifying antirheumatic drug } \\ \text { C } & \text { cytosine } \\ \text { CD40 } & \text { cluster of differentiation 40 } \\ \text { CI } & \text { confidence interval } \\ \text { CRP } & \text { C reactive protein } \\ \text { dbSNP } & \text { data base of single nucleotide polymorphism } \\ \text { DMARD } & \text { disease modifying antirheumatic drug } \\ \text { DNA } & \text { deoxyribonucleic acid } \\ \text { ERAP1 } & \text { endoplasmic reticulum aminopeptidase 1 } \\ \text { EULAR } & \text { European League against Rheumatism } \\ \text { G } & \text { guanine } \\ \text { GWAS } & \text { genome wide association study } \\ \text { HLA } & \text { human leukocyte antigen } \\ \text { IBD } & \text { inflammatory bowel disease } \\ \text { IFN } & \text { interferon } \\ \text { IL } & \text { interleukin } \\ \text { IL23R } & \text { interleukin 23 receptor } \\ \text { IRF5 } & \text { interferon regulatory factor 5 } \\ \text { K } \alpha & \text { Cronbach's alpha } \\ & \end{array}$




$\begin{array}{ll}\text { MAF } & \text { minor allele frequency } \\ \text { MHC } & \text { major histocompatibility complex } \\ \text { mSASSS } & \text { modified Stoke Ankylosing Spondylitis Spinal Score } \\ \text { NCBI dbSNP } & \text { National Center for Biotechnology Single Nucleotide } \\ & \text { Polymorphism database } \\ \text { NSAID } & \text { nonsteroidal antiinflammatory drug } \\ \text { OR } & \text { odds ratio } \\ \text { OR } & \text { odds ratio adaptive model } \\ \text { OR } & \text { odds ration multiplicative model } \\ \text { P } & \text { probability value (the level of statistical significance) } \\ \text { PCR } & \text { polymerase chain reaction } \\ \text { PTPN22 } & \text { protein tyrosine phosphatase, non-receptor type 22 } \\ \text { RA } & \text { (lymphoid) } \\ \text { SLE } & \text { rheumatoid arthritis } \\ \text { SNP } & \text { systemic lupus erythematosus } \\ \text { SpA } & \text { single nucleotide polymorphism } \\ \text { SLE } & \text { spondyloarthritis } \\ \text { T } & \text { systemic lupus erythematosus } \\ \text { TGF } \beta & \text { thymine } \\ \text { TNF } & \begin{array}{l}\text { tumor necrosis factor } \\ \text { TNFA }\end{array} \\ \text { UTR } & \text { untranslated region } \\ & \end{array}$




\section{Introduction $^{1}$}

\section{Topicality of the Thesis}

Ankylosing spondylitis (AS) is a systemic, chronic immune system mediated inflammatory arthritis - the form of spondyloarthritis ( $\mathrm{SpA}$ ) which mainly affects sacroiliac joints, axial skeleton with or without extraspinal manifestations (e. g. peripheral arthritis, uveitis, dactylitis etc.), inducing inflammation and structural damage of entheses, joints, bones and involved internal organs (de Winter et al., 2016). The most clinically relevant symptom is inflammatory back pain which occurs mainly at night and early morning followed by morning stiffness disturbing daily activities. The effect of inflammation is structural damage: an agressive and long-standing disease results in ankylosis of the sacroiliac joints and "bamboo" like spine (bony bridges made from the fusion of syndesmophytes and calcification of ligaments), leading to a significant decrease in spinal mobility and thus causing functional disability.

The first onset of AS clinical symptoms is usually observed at the age of 20 to 30 years (Rudwaleit, Haibel et al., 2009). Based on the epidemiological studies, in the European region AS prevalence is between $0.2 \%$ and $1.2 \%$ (Sieper et al., 2006). There are no precise data on the number of AS patients in Latvia.

Approximately $30 \%$ of AS patients may develop uveitis, inflammatory bowel disease (IBD) $-3-10 \%$, psoriasis in $10 \%$ of patients (de Winter et al., 2016). A proportion of AS patients may have damage of cardiovascular system, lungs and kidneys (Elewaut, Matucci-Cerinic, 2009). Data from several epidemiological studies confirm that higher incidence of extraarticular

${ }^{1}$ In the text, the name of the gene is italic (e. g. $H L A-B * 27$ ), the name of the genecoded protein is in regular font style (e. g. HLA-B27). 
manifestations is the result of uncontrolled systemic inflammation (el Maghraoui, 2011).

AS has a negative impact on the quality of life which is associated with disease activity and its caused functional impairment of daily activities (López-Medina et al., 2017). Importantly, the diagnosis of AS is still delayed by 8 to 10 years thus indicating the need for new diagnostic tests (Costantino et al., 2018).

In view of the epidemiological data on the disease, the economic aspects of the direct and indirect costs of the disease are crucial (Malinowski, Kawalec, 2015). In this case, timely diagnosis and targeted effective therapy would significantly reduce the indirect costs associated with work disability.

At the beginning of this century, treatment options for AS have progressed from symptom reduction to pathogenetic therapy with disease-modifying antirheumatic drugs (DMARDs), particularly tumour necrosis factor alpha $(\mathrm{TNF} \alpha)$ inhibitors. Early and effective AS therapy by reducing disease activity (inflammation) prevents the progression of structural damage of the joints and bones (Baraliakos et al., 2014; Molnar et al., 2018). However, not all patients develop remission as a result of the therapy. For example, up to $40 \%$ of patients receiving $\mathrm{TNF} \alpha$ inhibitors do not respond or cannot tolerate the treatment or develop a loss in efficacy over time (Braun et al., 2017). As known, some (more than a quarter) of the drugs involved in clinical trials are not registered due to lack of efficacy (Nelson et al., 2015). Genetic research-supported drug development helps prevent the risk of treatment failure. The next level in the care of AS is cure of the disease and, more importantly, prevention of its development. One of the means to achieve these disease management goals is to identify and understand the genetic basis of the disease.

The course of AS disease can vary - axial form only, axial and peripheral form, axial form with extraspinal manifestations and rapid progression etc. Currently in clinical practice there is no unambiguous marker that can predict the 
development of disease manifestation in a particular individual with AS. The genetic basis of AS, which is formed by analysing the candidate genes and the proteins encoded by them involved in the pathogenesis of AS and its clinical manifestations, is also important in exploring this issue.

Genome wide association studies (GWAS) indicate the breadth of pleiotropy between different diseases - where one variant can affect the risk of developing multiple diseases; sometimes the effect may be the opposite, that is, by promoting the development of one disease but at the same time protecting from the risk of developing another disease (Brown, Wordsworth, 2018). Knowledge of the genetic basis of the disease is an essential safety aspect for targeted drug development.

Genetic polymorphism varies among different populations and regions and the genetic card of one population in different regions is not identical, thus partly clarifying the varied AS prevalence in different geographical regions and countries (Brown, Worsworth, 2018). It justifies the possible differences in the results of the conducted studies and indicates the need for geographically targeted studies, especially for small populations.

According to the current classification of SpA AS belongs to the axial group of SpA. Axial SpA group includes non-radiographic and radiographic axial SpA - the difference between these groups is based on the absence or presence of structural damage in sacroiliac joints radiographs, respectively (Rudwaleit, van der Heijde et al., 2009). Research data on whether these conditions are two stages of the same disease or different diseases are contradictory (Mease et al., 2018; Proft, Poddubnyy, 2018; Robinson et al., 2013). Therefore, clinical and genetic analysis of a relatively homogeneous group of AS patients meeting the New York criteria (van der Linden et al., 1984) is of particular importance to identify prospectively those patients with inflammatory back pain who will not develop AS in the future. Understanding the risk of developing the disease would allow for an objective assessment of the 
benefit-risk ratio when deciding on the waiting approach or therapy and its type to be initiated.

Based on family and twin studies, AS is known to be highly heritable, with $>90 \%$ of the risk of developing the disease determined genetically (Brown, 2008). There is considerable data suggesting that knowledge about HLA-B*27 (human leukocyte antigen B27), a gene encoded in major histocompatibility complex (MHC), though important, is not sufficient to explain the genetic epidemiology of AS (Brown et al., 2000). Thus, only a small proportion of $H L A-B * 27$ positive individuals in the general population develop AS, suggesting that there are other susceptibility factors and confirming AS not being a monogenic disease. To date, 115 loci have been identified, contributing to $28 \%$ of the genetic variation in the disease (Brown, Wordsworth, 2018). Non-HLA genes identified in recent decades include genes encoding proteins involved in interferon or TNF $\alpha$ signaling pathway and transcription, the IL-23/IL-17 cascade, or CD8+ lymphocyte differentiation, and essential for antigen presentation, including mucosal immunity factors, M1-aminopeptidases (Brown, Wordsworth, 2018; Ruyssen-Witrand et al., 2019). These factors are important components of the pathogenesis of AS (Pederson, Maksymowych, 2018). Since AS is a polygenic disease, an analysis of each separate stage of its pathogenesis will allow a more complete understanding of the course of the disease and usage of safe treatment within personalized medicine.

The two main remaining challenges in the research of AS genetic aspects are to identify genetic polymorphisms responsible for the large proportion of heritability of the disease that remains unexplained, and to determine functional mechanisms underpinning those genetic associations (Li, Brown, 2017). Consequently, there are several trends in the genetic research of AS: to find out which genes are associated with the disease; to determine the relation of disease- 
associated gene polymorphisms with variants of disease phenotypic expression; to analyse the association of these gene polymorphisms with the risk of simultaneous development of several other diseases; to analyse gene polymorphisms linked with other diseases in relation to the risk of developing AS.

During the evaluation of publications on the pathogenesis and genetic aspects of AS and designing a study on the AS genetic profile, the selection of non-HLA candidate genes in close relation to the pathogenesis was based on the following several aspects:

- a known association with AS which has been proven in more extensive studies (ERAP1, IL23R) (Li, Brown, 2017; WTCCC et al., 2007);

- the association with AS is less clearly defined in different populations (for example, TNFA (Manolova et al., 2014), IL10 (Xia et al., 2018), TGFß1 (Jaakkola et al., 2004));

- a possible involvement of gene-encoded protein in inflammation or osteoproliferation in AS, by analysing genes not yet widely evaluated in AS (for example, CD40 (Croft, Siegel, 2017), TGFB1 (Jaakkola et al., 2004), PTPN22 (Sode et al., 2018));

- a possible association of gene encoded protein with phenotypic extraspinal manifestations of AS - uveitis and peripheral arthritis (for example, IL1O (Chu et al., 2012), IRF5 (Márquez et al., 2013));

- the gene association with other rheumatic diseases, for example, rheumatoid arthritis (RA) (PTPN22 (Criswell et al., 2005; Tizaoui et al., 2019)), CD40 (Peters et al., 2009)), IBD (IRF5 (Gathungu et al., 2012)), systemic sclerosis (TGFB1 (Zhang et al., 2013)), in order to understand the potential role of a single gene in the development of multiple diseases and to predict the safety and efficacy aspects of therapy. 
In view of the epidemiological, clinical data, disease modalities and trends in modern personalized medicine approaches to AS care, it is crucial to diagnose the disease timely and to treat it using targeted and effective tools. Genetic research is important to determine the risk of developing the disease, to predict its course and thus to prevent the possibility of irreversible damage. In order to facilitate the development of a holistic care approach for AS patients, a study was conducted to identify some of the genetic aspects of AS and their relationship to clinical manifestations, including the most frequent extraspinal manifestations such as uveitis and peripheral arthritis.

\section{Hypothesis of the Thesis}

Polymorphisms of the candidate genes are associated with ankylosing spondylitis and its clinical manifestations - uveitis and peripheral arthritis, treatment efficacy with tumor necrosis alpha inhibitors.

\section{Aim of the Thesis}

To investigate the association and its clinical significance between the polymorphisms of the candidate genes and the haplotypes of different combinations of these polymorphisms in relation to ankylosing spondylitis and its clinical course, treatment efficacy with tumour necrosis alpha inhibitors.

\section{Objectives of the Thesis}

1. To select ankylosing spondylitis patients by using an original questionnaire and characterise the clinical profile of ankylosing spondylitis patients as well as clinical manifestations - uveitis and peripheral arthritis.

2. To determine association between the polymorphisms of the candidate genes and ankylosing spondylitis by comparing the distribution of alleles and genotypes in case and control groups. 
3. To determine association between the haplotypes of different combinations of the polymorphisms of the candidate genes and ankylosing spondylitis by comparing case and control groups.

4. To determine association between the alleles and genotypes of the polymorphisms of the candidate genes and clinical manifestations of ankylosing spondylitis - uveitis and peripheral arthritis.

5. To determine association between the haplotypes of different combinations of the polymorphisms of the candidate genes and clinical manifestations of ankylosing spondylitis - uveitis and peripheral arthritis.

6. To determine association between the alleles and genotypes of the polymorphisms of the candidate genes and biomarkers of ankylosing spondylitis chosen in the study (the age of the manifestation of first clinical symptoms, the assessment of cervical and lumbar spine radiographic changes, the assessment of the treatment efficacy with tumor necrosis factor alpha inhibitors during the first year of usage). 


\section{Study material and methods}

\subsection{Included persons, inclusion and exclusion criteria}

The prospective study includes patients treated in the Centre of Rheumatology (inpatient and outpatient departments) of Pauls Stradins Clinical University Hospital during the time period from 2011 till 2013.

The inclusion criteria: diagnosis according to the modified New York criteria for AS (van der Linden et al., 1984). The study included patients who developed their first clinical symptoms after the age of 18 years.

The exclusion criteria: other type of chronic or autoimmune inflammatory arthritis (for example, psoriatic arthritis), systemic lupus erythematosus, psoriasis, multiple sclerosis, inflammatory bowel disease, type I diabetes mellitus, thyrotoxicosis, acute or chronic infection, depression or other psychiatric diseases (diagnosed or treated by a psychiatrist), diseases of central nervous system, alcohol or other substance abuse.

The control group was formed by using data from the Genome Database of Latvian population of the Latvian Biomedical Research and Study Centre. This group included potentially healthy persons without known chronic inflammatory diseases and was matched with the case group according to age and place of residence.

AS patients included in the study were retrospectively evaluated for the efficacy of the first year of treatment with TNF $\alpha$ inhibitors during the time period till March 2019.

The study was approved by the Ethics Committee of Rīga Stradiņš University. The inclusion of genetic data from healthy individuals in the study was based on the consent of the Central Medical Ethics Committee. Prior to inclusion, all individuals signed the informed consent form. 


\subsubsection{Demographic characteristics of ankylosing spondylitis patients and control group}

The study included 98 AS patients, of whom 90 (91.84\%) were males and eight ( $8.16 \%$ ) females with the mean age of $39.28 \pm 15.69$ (range 20-60) years. The control group data of 154 healthy individuals of the population of Latvia, of whom $128(83.12 \%)$ were male and 26 (16.88\%) female, were analysed. The mean age of the control group was $40.17 \pm 9.44$ years (range 14-80).

Entire patient group was analysed in the study, as well as depending on the presence of uveitis and/or peripheral arthritis, dividing AS patients into four subgroups (see Fig. 1.1).

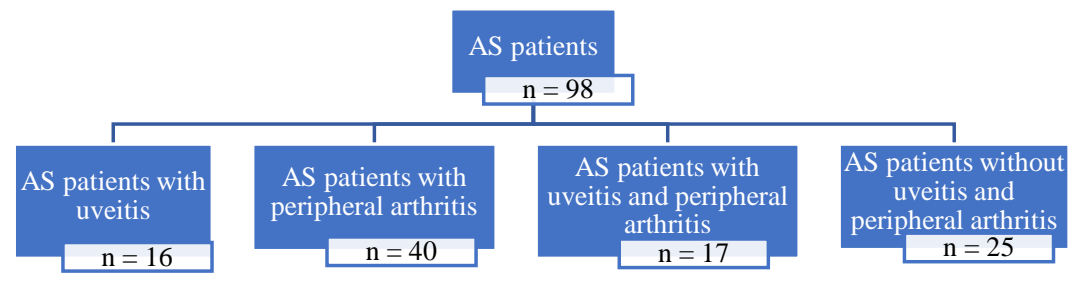

Figure 1.1. Classification of ankylosing spondylitis (AS) patients based on uveitis and/or peripheral arthritis data

\subsubsection{Biological material used in the study}

Clinical tests were performed at the Biochemistry Laboratory of Pauls Stradins Clinical University Hospital. In AS patients blood c-reactive protein (CRP) level was determined, which was considered elevated at the level above $5 \mathrm{mg} / \mathrm{L}$. Isolation of deoxyribonucleic acid (DNA) from blood samples for the 
determination of genetic polymorphisms was performed in the Laboratory of the Latvian Biomedical Research and Study Centre.

\subsection{Clinical and radiological investigation methods}

Aspects of medical history

Each AS patient responded to the questions included in the survey questionnaire. The questions contained information on age at onset of the first symptoms of the disease, duration of the disease, evaluation of patient's disease activity and pain associated with the disease during the past week (0-10, where 0 - no symptoms and 10 - very severe manifestation), ocular symptoms (uveitis) and extraspinal joints, treatment, evaluating the patient's information and medical documentation data, including comorbidities, family history, treatment applied. Disease duration is defined in accordance with the concept developed in 2006 (Davis et al., 2006).

At the enrollment in the study, the presence of uveitis was determined on the basis of an ophthalmologist's opinion. Its history was established by the use of medical documentation.

\section{Physical examination}

Spinal mobility using BASMI (Bath Ankylosing Spondylitis Metrological Index) (Jenkinson et al., 1994) and 44 peripheral joints determining pain and synovitis during palpation (Zochling, Braun, 2005) were evaluated in AS patients during clinical examination. BASMI was calculated using a three-point evaluation method. Hip joint involvement was classified as manifestation of axial disease (Zochling, Braun, 2005).

Evaluation of physical function in AS patients

AS patients completed a self-evaluation questionnaire of physical function - BASFI (Bath Ankylosing Spondylitis Functional Index) consisting of ten questions (Calin et al., 1994). The questionnaire was validated in Latvian and 
Russian. Each item was assessed on the ten point basis: 0 - easy to perform the described action or movement and 10 - impossible to perform it). The sum of all answers divided by ten indicates the severity of functional disability.

The value of Cronbach's alpha $(\mathrm{K} \alpha)$ was determined to verify whether the questionnaire questions could be combined for self-assessment analysis of the functional ability in a given patient group. The BASFI questionnaire $\mathrm{K} \alpha$ was 0.96 indicating that all ten questions in this group could be used for the self-evaluation of the functional ability.

Evaluation of AS disease activity and treatment efficacy using bDMARDs BASDAI (Bath Ankylosing Spondylitis Disease Activity Score) is a six-item questionnaire to be completed by the patient evaluating fatigue, back pain, peripheral joint pain, enthesial pain and morning stiffness (its duration and intensity) from 0 to 10 ( 0 - no complaints and 10 - very severe manifestation) for the last week (Garrett et al., 1994). The calculation of the BASDAI result by a certain formula makes it possible to determine whether the disease is active $(\mathrm{BASDAI} \geq 4)$ or inactive (BASDAI $<4$ ). The questionnaire has been validated in Latvian and Russian. The value of Cronbach's alpha $(\mathrm{K} \alpha)$ was determined to verify whether questionnaire items could be combined for self-assessment analysis of the disease activity in a given patient group. The BASDAI questionnaire $\mathrm{K} \alpha$ was 0.87 indicating that all six questions in this group could be used for the self-evaluation of the disease activity.

The second disease evaluation index is ASDAS (Ankylosing Spondylitis Disease Activity Score). This score includes patient-reported assessment of back pain (BASDAI question 2), disease activity evaluation (0-10), peripheral joint pain/swelling (BASDAI question 3), duration of morning stiffness (BASDAI question 6) and CRP (mg/L) (Lukas et al., 2009). When calculating the index using the formula, the degree of AS activity is determined. 
In the analysis of the patient group $(\mathrm{n}=55)$ taking TNF $\alpha$ inhibitors, ASAS-EULAR recommendations on BASDAI dynamics was used to assess the efficacy of therapy: an improvement in this index by two or more units $(0-10)$, calculated at least 12 weeks from initiation, was considered to be a therapy effect (van der Heijde et al., 2017). The efficacy of TNF $\alpha$ inhibitors was evaluated over the first 12 months of therapy, calculating BASDAI every three to six months. A further analysis of genetic aspects was carried out by dividing patients into two groups: treatment effifacy (BASDAI $<4$ or reduction in BASDAI by two units from the baseline data without deterioration during the year) and treatment inefficacy group (decrease in BASDAI less than two units from baseline data at the end of the assessment period).

\section{Radiological investigation}

Cervical and lumbar spine radiographs for AS patients were performed in the Institute of Radiology of the Pauls Stradins Clinical University Hospital and subsequently analysed by a certified radiologist according to the mSASSS (modified Stoke Ankylosing Spondylitis Spinal Score) method (Creemers et al., 2005; Wanders et al., 2004).

Randomly selected radiograph data of 18 AS patients were evaluated by another independent certified radiologist to verify compliance with the mSASSS assessment. Measure of agreement of the radiologists' evaluation was 0.94, Pearson's correlation coefficient -0.94 . The results showed that the assessments provided by the first radiologist were accurate and consistent with the terms of the method of mSASSS.

\subsection{Selected biomarkers of ankylosing spondylitis}

On the basis of data from scientific publications and topical issues of the clinical work, we selected biomarkers describing AS disease for further analysis: 
1) age at onset of first clinical symptoms; 2) assessment of structural damage (mSASSS) analysed in the context of the disease duration; 3) assessment of the efficacy of the first year of treatment with TNF $\alpha$ inhibitors (BASDAI $<4$ or decrease of BASDAI for two units from baseline data without deterioration during the year); 4) disease transition into an inactive form (BASDAI < 4) during the first year of treatment with TNF $\alpha$ inhibitors; 5) tendencies of changes in the disease activity assessment (BASDAI) during the first treatment year with TNF $\alpha$ inhibitors.

\subsection{Detection of genetic polymorphism}

A peripheral blood sample was collected from patients and phenotypic information was obtained according to the protocols of the Genome Database of Latvian population (Rovite et al., 2018). To conduct the genetic analysis, the genomic DNA was extracted from the Genome Database of Latvian population and was further used for the determination of selected genetic polymorphisms.

For the determination of biallelic polymorphisms IRF5 rs10954213, rs2004640, rs3757385, CD40 rs4810485, ERAP1 rs10050860, rs30187, rs26653, IL23R rs10889677, rs11209026, rs2201841, PTPN22 rs2476601 and TGFß1 rs1800469, rs1800470 a real-time polymerase chain reaction (PCR) was performed using commercially available TaqMan reagent kits TaqMan Assays (Thermo Fisher Scientific, USA) individually for each SNP.

DNA found in individuals from the Genome Database of Latvian population was diluted to $7 \mathrm{ng} / \mu \mathrm{l}$ and $28 \mathrm{ng}$ genomic DNA was used for the reaction. Reaction mixture for one reaction: $\mathrm{H}_{2} \mathrm{O}-5 \mu \mathrm{l}$; TaqMan Universal PCR Master Mix - 4,75 $\mu \mathrm{l}$; TaqMan probe 0,25 $\mu \mathrm{l}$; genomic DNA $4 \mu \mathrm{l}$. The prepared reaction mixture was inserted into the Real Time PCR system ViiA 7 (Applied 
Biosystems, USA), where amplification and genotyping were carried out in accordance with the manufacturer's instructions.

The Sanger sequencing of both DNA strands for the analysis of ILIO rs1800896 and TNFA rs1800629 was performed: IL10 5'TTCCCCAGGTAGAGCAACAC-3' and 5'-ATCCTCAAAGTTCCCAAGCA3' (685 bp); TNFA: 5'-ACAGGCCTCAGGACTCAACA-3' and 5'GCACCTTCTGTCTCGGTTTC-3' (364 bp).

The same nucleotides that were used for polymerase chain reaction were also used for the sequencing reaction. Polymorphism was named by analysing electropherograms.

\subsection{Statistical analysis of data}

All analyses were conducted using the IBM SPSS Statistics, version 23.0 (IBM Corp., Armonk, N.Y., USA, 2015).

Data analysis steps and statistical methods applied:

- estimation of the normal distribution of cases and control data using Shapiro-Wilk or Kolmogorov-Smirnov tests;

- comparison of mean values: parametric data method T test or one-way analysis of variance (ANOVA) or non-parametric data method - the Mann-Whitney or the Kruskal-Wallis test;

- determination of the strength of the relationship between nominal and numeric variables, using either the $\eta$ (eta), or between two numerical parameters, using the Pearson's r or the Spearman's $\rho$ test;

- determination of regularities using the regression analysis;

- determination of the measure of agreement and Kappa coefficient by comparing the matching of values of the two certified radiologists' mSASSS. The number of patients analysed by the other certified radiologist according to 
the mSASSS method was defined based on the guidelines of the minimum required sample size for Cohen's Kappa coefficient (Bujang, Baharum, 2017a; Bujang, Baharum, 2017b; Temel, Erdogan, 2017). Because the value of mSASSS is a numerical, the Kappa coefficient is equivalent to Pearson's correlation coefficient. The measure of agreement should be at least 0.80 (80 \%) and the Kappa coefficient at least 0.80 to consider the assessments of the first radiologist as relevant and accurate (McHugh, 2012);

- determination of Cronbach's alpha $(\mathrm{K} \alpha)$ for BASFI and BASDAI using reliability analysis;

- determination of distribution of frequencies of the SNPs genotypes according to the Hardy-Weinberg equilibrium prior the selection of SNPs and statistical analysis of polymorphisms using heterozygosity index;

- development of combinations of SNPs haplotypes in addition to allelic and genotypic data using DNASp version 6.11.01 (Rozas et al., 2017);

- determination of the existence of a statistically significant difference in the analysis of the relationship between the two nominal variables using $\chi^{2}$ criterion or Pearson's $\chi^{2}$ method or Fisher's exact test;

- determination of association between nominal variables, using Cramer's V;

- determination of polymorphism (allele, genotype, haplotype) effects on the disease probability (clinical relationship) using odds ratio (OR) and confidence interval (CI) in $95 \%$ cases. OR determined using statistical programme PAST (Paleontological Statistics, ver. 3.12; Hammer et al., 2001). OR calculations used adaptive and multiplicative models. If the OR is 1 , the allele (genotype) of specific locus does not increase the risk for the disease. If $\mathrm{OR}>1$, the risk increases; if $\mathrm{OR}<1$, the risk decreases. If $\mathrm{OR}>2$, the disease risk is very high; if $\mathrm{OR}>3$, the disease risk is clinically significant. OR value less than 1 indicates the protective allele (genotype) (Uthoff et al., 2002). 
When analysing differences between groups or relationship between variables, $\mathrm{P}$ value less than $0.05\left(5.00 \times 10^{-2}\right)$ was considered statistically significant. 


\section{Results}

\subsection{Characteristics of ankylosing spondylitis patients}

Analysis of whole AS group

The study analysed the demographic and clinical data of 98 AS patients. Mean disease duration was $13.79 \pm 8.29$ years. The average age at onset of the first symptoms was $26.33 \pm 6.82$ years. An active disease has been observed in the majority of patients in the analysis of the mean parameters of the activity assessment: CRP $16.42 \pm 21.20 \mathrm{mg} / \mathrm{L}, \mathrm{BASDAI} 4.72 \pm 2.26$, ASDAS $_{\mathrm{CRP}} 3.01 \pm$ 1.38. The assessment of fatigue and back pain averaged above five $-5.34 \pm 2.50$ and $5.55 \pm 2.94$, respectively. The mean score for extraspinal joint and global disease activity evaluation was on average below five $-3.41 \pm 2.89$ and $4.94 \pm 2.30$, respectively. The mean scores of BASFI and BASMI showed impairment of these activities of $3.72 \pm 2.69$ and $3.89 \pm 2.60$, respectively. In the analysis of extraspinal manifestations of AS at the time of enrollment in the study, $33(33.67 \%)$ patients had a history or presence of uveitis and $57(58.16 \%)$ patients had peripheral arthritis.

An analysis of the groups of medicines used to treat AS patients showed that a total of $73(74.49 \%)$ patients were taking NSAIDs, and $25(25.51 \%)$ patients not taking NSAIDs at all. Ten $(10.20 \%)$ patients received glucocorticoid. In the sDMARDs analysis, four $(4.08 \%)$ patients received methotrexate and $34(34.69 \%)$ patients received sulfasalazine. During the study inclusion period from 2011 till 2013 bDMARDs (TNF $\alpha$ inhibitors) were taken by 18 (18.37\%) patients. Between 2011 and March 2019, 55 (56.12\%) AS patients enrolled in the study were treated with bDMARDs (TNF $\alpha$ inhibitors) therapy. 


\section{Characteristics of AS patients with uveitis}

Two groups of $33(33.67 \%)$ and $65(66.33 \%)$ patients were formed when dividing patients according to the history or presence of uveitis at the time of inclusion in the study. The groups were mutually compared according to the parameters chosen in the thesis. A statistically significant difference was found in only two parameters characterising the disease - the duration of the disease

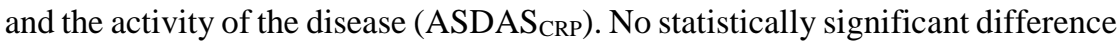
was identified during the analysis of the other parameters.

In patients with uveitis, the mean duration of the disease was higher $(17.00 \pm 7.93$ years $)$ compared to patients without uveitis $(12.15 \pm 8.04$ years $)$ $\left(\mathrm{P}_{\mathrm{MV}}=5.61 \times 10^{-3} ; \eta=0.28\right)$.

AS patients with uveitis were more likely to have low to moderate disease activity compared to the group without uveitis which had higher disease activity. These differences were statistically significant $\left(\mathrm{P}_{\chi}=9.84 \times 10^{-3} ; \mathrm{V}=0.34\right)$.

\section{Characteristics of AS patients with peripheral arthritis}

Two groups of $57(58.16 \%)$ and $41(41.84 \%)$ patients were formed by stratifying patients according to the history or presence of peripheral arthritis at the time of the enrollment in the study. The two groups were compared with each other by a number of parameters. A statistically significant difference was found for two disease-specific parameters - CRP and joint pain self-assessment. In the analysis of other parameters, we did not obtain a statistically significant difference within the study.

In patients with peripheral arthritis, the mean CRP was statistically higher compared to patients without peripheral arthritis $(21.86$ vs. $8.85 \mathrm{mg} / \mathrm{L}$; $\mathrm{P}_{\mathrm{MV}}=3.66 \times 10^{-3} ; \eta=0.30$ ). Joint pain self-assessment was also statistically higher in patients with peripheral arthritis compared to patients without peripheral arthritis (4.54 vs. $1.83 ; \mathrm{P}_{\mathrm{MV}}=3.26 \times 10^{-6} ; \eta=0.47$ ). 


\section{Characteristics of AS patients with uveitis and/or peripheral arthritis}

By dividing AS patients into four subgroups according to the presence or absence of extraspinal manifestations (uveitis and/or peripheral arthritis), it was found that four parameters - disease duration, CRP, ASDAS ${ }_{\mathrm{CRP}}$, self-reported joint pain - had a statistically significant difference.

The longest duration of the disease (mean $18.00 \pm 8.94$ years) was in the group with both extraspinal manifestations, but the shortest duration of the disease (mean $11.92 \pm 8.38$ years) was found in the group without both manifestations $\left(\mathrm{P}_{\mathrm{KV}}=4.60 \times 10^{-2} ; \eta=0.29\right)$.

The highest CRP mean value was found in AS patients with peripheral arthritis alone $(24.32 \pm 27.95 \mathrm{mg} / \mathrm{L})$. The lowest mean CRP was determined in the group of patients with uveitis alone $(5.91 \pm 6.76 \mathrm{mg} / \mathrm{L})$. In the group with uveitis and peripheral arthritis it was $16.08 \pm 15.04 \mathrm{mg} / \mathrm{L}$. The mean value of CRP in the group without both manifestations was $10.74 \pm 12.51 \mathrm{mg} / \mathrm{L}$. Comparison of mean CRP values of four subgroups resulted in statistically significant difference $\left(\mathrm{P}_{\mathrm{KV}}=1.57 \times 10^{-2} ; \eta=0.34\right)$.

Similarly, high disease activity $\left(\mathrm{ASDAS}_{\mathrm{CRP}}\right)$ was most frequently found in the group with only peripheral arthritis $(57.50 \%)$ and was the least frequent in the group with uveitis alone $(6.25 \%)$, whereas the highest proportion of inactive and low disease activity $\left(\mathrm{ASDAS}_{\mathrm{CRP}}\right.$ ) was determined in the group with uveitis and without peripheral arthritis $(25.00 \%$ in both groups of activity assessment $)\left(\mathrm{P}_{\mathrm{KV}}=2.20 \times 10^{-3} ; \mathrm{V}=0.26\right)$.

In the analysis of the average assessment of the visual pain score of the joints in four patient groups, the highest value was found in the AS patient group with both manifestations and the lowest value was found in the group only with uveitis (4.76 vs. $\left.1.31 ; \mathrm{P}_{\mathrm{KV}}=4.29 \times 10^{-5} ; \eta=0.48\right)$.

While comparing the other parameters in the analysis of four subgroups of AS patients, no statistically significant difference was obtained. 


\subsection{Polymorphisms of the ankylosing spondylitis candidate genes}

A total of 15 SNPs, which are localised in eight genes, were analysed. AS candidate genes are localised on chromosomes 1, 5, 6, 7, 19 and 20.

The candidate gene polymorphisms are located at different gene positions: six SNPs in the exon, four SNPs in the intron, two SNPs in the pregene region and the 3'UTR (untranslated region), one SNP in the 5'UTR.

While comparing the frequency of minor alleles (MAF) of the SNPs in the 1000 Genomes Project of the European population (https://www.ncbi.nlm.nih.gov/bioproject/PRJEB6930)) and the study data, two SNPs differ: $G$ alelle of the IRF5 rs2004640 and $T$ allele of the TGF $\beta 1$ rs 1800469 are major alleles in the control group unlike MAF of the European population. In the case of PTPN22 rs2476601, the frequency of the minor allele in control group varies only at the frequency value: in Europe, the MAF is 0.0094, and in our study control group, 0.227; in the case of TNFA rs1800629: in Europe, the MAF is 0.134 , in our study control group -0.247 . The other SNPs MAF are similar to European population data.

\subsection{The link of ankylosing spondylitis candidate gene polymorphisms to the disease}

In the analysis of the genetic equilibrium of all loci, it was found that the loci which had only two genotypes were not in the Hardy-Weinberg equilibrium: IRF5 rs2004640, IL23R rs11209026, PTPN22 rs2476601, TNFA rs1800629 and $T G F \beta 1$ rs 1800469. No heterozygous form was found in the mentioned SNPs in AS patients and control group. The only locus, in which genotypes were not in the Hardy-Weinberg equilibrium in one of the groups but all three genotype 
forms were present, was ERAP1 rs30187 (the analysis revealed that heterozygous $G A$ genotype was more frequent than $G G$ genotype formed by the major allele).

\section{Distribution of the alleles}

In the analysis of the distribution of alleles of all 15 SNPs in the AS patient and control groups, a statistically significant difference was observed in CD4O rs4810485, TNFA rs1800629 and PTPN22 rs2476601. For the rest of the SNPs, no statistically significant difference was identified when comparing the case and control groups.

In the $C D 40$ rs 4810485 , the minor allele was $T$ in both groups, but it was $11 \%$ more frequent in the case group (28.57 vs. $17.53 \% ; \mathrm{P}_{\chi}=3.45 \times 10^{-3}$; $\mathrm{V}=0.13)$. The relationship between the AS and the allelic distribution was weak. This allele had a trend of risk form but the risk was not clinically significant $(\mathrm{OR}=1.88[1.23 \ldots 2.88])($ see Fig. 2.1).

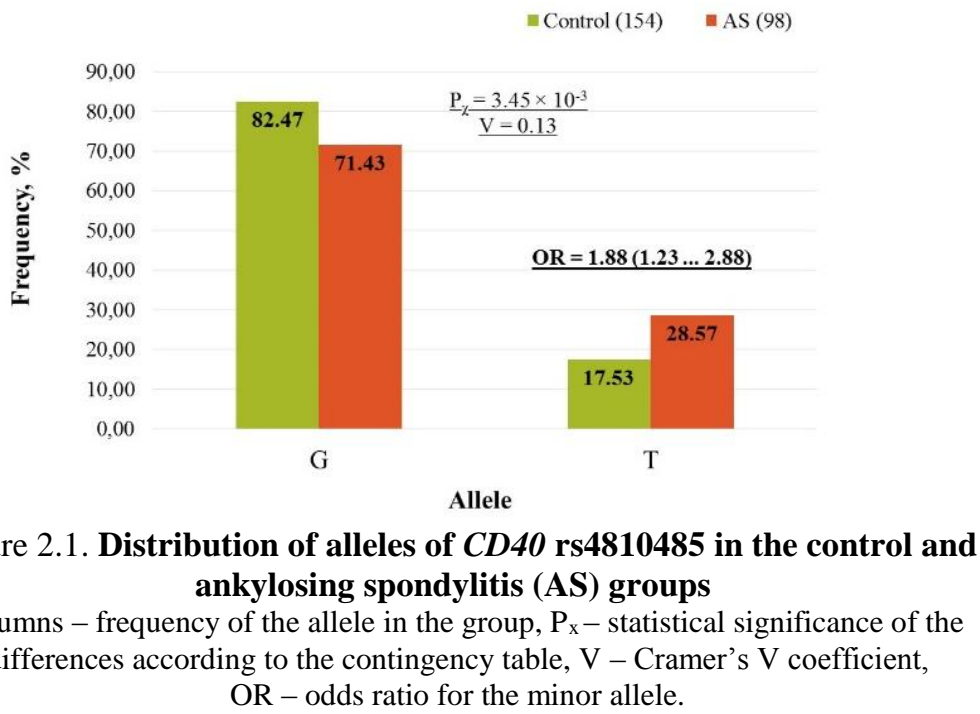


In the case of TNFA rs1800629 polymorphism, the minor allele in both groups was $A$. In the AS group it was $14 \%$ less common than in controls (10.20 vs. $24.68 \% ; \mathrm{P}_{\chi}=5.50 \times 10^{-5} ; \mathrm{V}=0.18$ ) (see Fig. 2.2). The $A$ allele showed a tendency for a protective allele that reduced the risk of AS $(\mathrm{OR}=$ $0.35[0.20 \ldots 0.59])$.

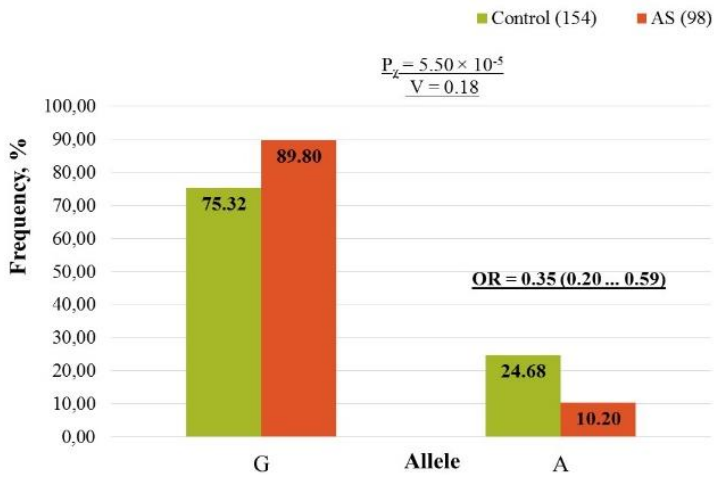

Figure 2.2. Distribution of alleles of TNFA rs1800629 in the control and ankylosing spondylitis (AS) groups

Columns - frequency of the allele in the group, $\mathrm{P}_{\mathrm{x}}$ - statistical significance of the differences according to the contingency table, V - Cramer's V coefficient, OR - odds ratio for the minor allele.

In the PTPN22 rs2476601 polymorphism, the minor allele was $T$ in both groups, but this allele was $10 \%$ more frequent in the AS group (32.65 vs. $22.73 \% ; \mathrm{P}_{\chi}=1.39 \times 10^{-2} ; \mathrm{V}=0.11$ ) (see Fig. 2.3). There was a trend for the risk, but it was not clinically significant $(\mathrm{OR}=1.65[1.11 \ldots 2.46])$. 


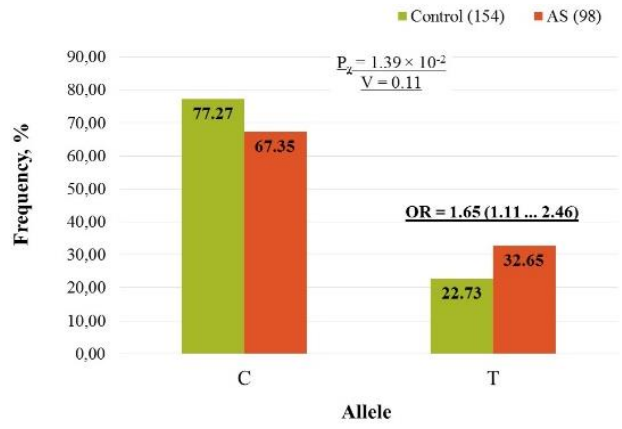

Figure 2.3. Distribution of alleles of PTPN22 rs2476601 in the control and ankylosing spondylitis (AS) groups

Columns - frequency of the allele in the group, $\mathrm{P}_{\mathrm{x}}$ - statistical significance of the differences according to the contingency table, $\mathrm{V}$ - Cramer's V coefficient, OR - odds ratio for the minor allele.

\section{Distribution of the genotypes}

The statistically significant difference between the AS and the control group in the genotype distribution remained only for two SNPs: CD40 rs4810485 and TNFA rs1800629.

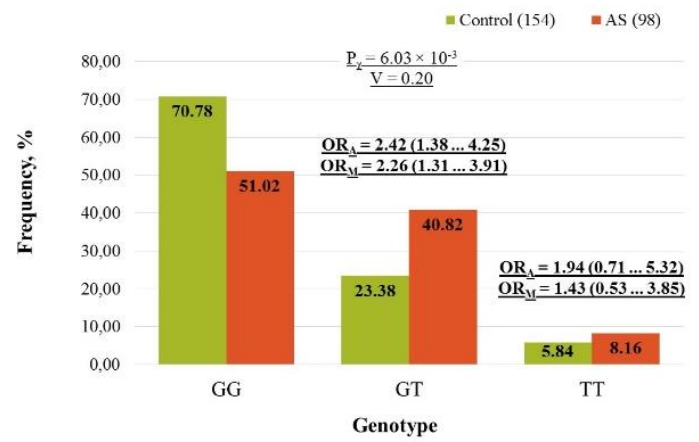

Figure 2.4. Distribution of genotypes of $C D 40$ rs4810485 polymorphism in the control and ankylosing spondylitis (AS) group

Columns - frequency of the genotypes in the group, $\mathrm{P}_{\mathrm{x}}$ - statistical significance of the differences according to the contingency table, V - Cramer's V coefficient, OR odds ratio for the risk genotype. 
In the case of $C D 40$ rs 4810485 , the most frequent genotype was $G G$ (see Fig. 2.4). The distribution of all three genotypes in the control and AS groups was different $\left(\mathrm{P}_{\chi}=6.03 \times 10^{-3} ; \mathrm{V}=0.20\right)$, and a statistically significant association was found between AS and genotypes. Of all three genotypes, two genotypes in the adaptive and multiplicative model showed signs of risk genotypes. For the $G T$ genotype, the OR was 2.42 [1.38 ... 4.25] in the adaptive model and $2.26[1.31 \ldots 3.91]$ in the multiplicative model. In both cases a high but not clinically significant level of risk was seen. In addition, it should be noted that the $G G$ form had markedly high levels of protective genotype in the multiplicative model $(\mathrm{OR}=0.43[0.25 \ldots 0.73])$.

In the case of TNFA rs1800629, only two genotypes were detected in both groups: homozygous forms of both alleles. Of the genotypes detected, the rare $A A$ genotype was the protective form ( $\mathrm{OR}=0.35[0.16 \ldots 0.73]$ ) (see Fig. 2.5). This genotype was found to be $24.68 \%$ in the control group and twice less in the AS group $-10.20 \%\left(\mathrm{P}_{\chi}=4.35 \times 10^{-3} ; \mathrm{V}=0.18\right)$. The $G G$ genotype was a form of risk $\left(\mathrm{OR}_{\mathrm{M}}=2,88[1,36 \ldots 6,10]\right)$.

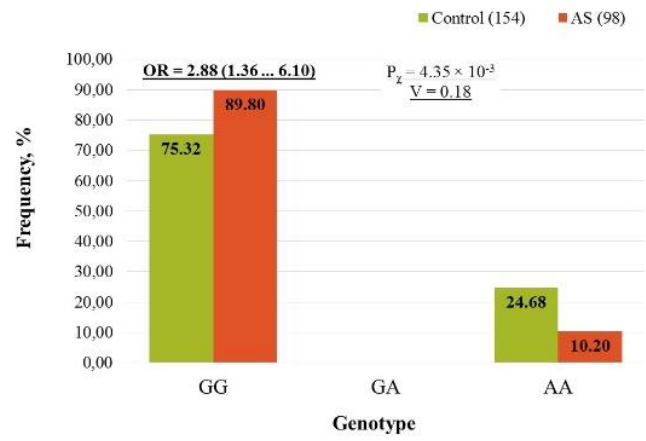

Figure 2.5. Distribution of genotypes of TNFA rs1800629 in the control and ankylosing spondylitis (AS) group

Columns - frequency of the genotypes in the group, $P_{x}-$ statistical significance of the differences according to the contingency table, $\mathrm{V}$ - Cramer's $\mathrm{V}$ coefficient,

$\mathrm{OR}$ - odds ratio for the risk genotype. 


\subsection{The link of ankylosing spondylitis candidate gene polymorphisms to the extraspinal manifestations of the disease - uveitis and peripheral arthritis}

All samples of AS patients were divided into smaller groups following the presences of uveitis or peripheral arthritis. Uveitis was identified in 33 $(33.67 \%)$ patients, peripheral arthritis - in 57 (58.16\%) patients.

The relationship of candidate gene polymorphisms of AS to uveitis

Analysis of the distribution of the alleles of the entire 15 SNPs following the presence of uveitis showed that a statistically significant difference was observed for ILIO rs1800896 (see Fig. 2.6), which was not linked to the disease as a whole.

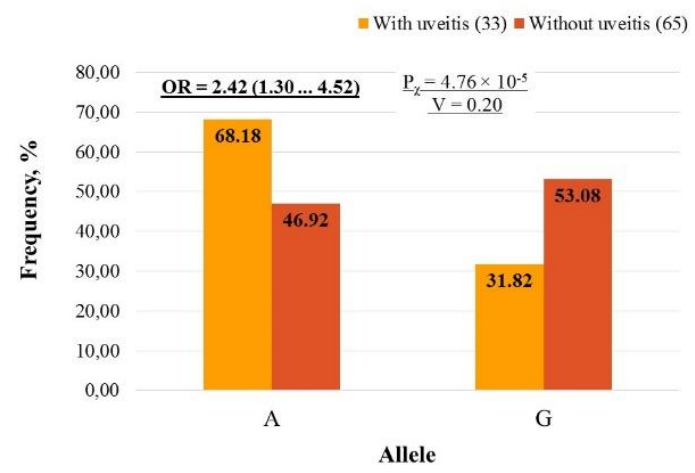

Figure 2.6. Distribution of $I L 10$ rs1800896 alleles in the ankylosing spondylitis group with and without uveitis

Columns - frequency of the alleles in the group, $P_{x}-$ statistical significance of the differences according to the contingency table, V - Cramer's V coefficient, $\mathrm{OR}$ - odds ratio for the risk allele. 
The minor allele of $I L 10 \mathrm{rs} 1800896$ was $G$. In the group with uveitis, this allele was $21 \%$ less frequent than in the group without uveitis (31.82 vs. $\left.53.08 \% ; \mathrm{P}_{\chi}=4.76 \times 10^{-5} ; \mathrm{V}=0.20\right)$. The $G$ allele was in the protective form against the development of uveitis $(\mathrm{OR}=0.41[0.22 \ldots 0.47])$. The major $A$ allele was the risk form for the ocurrence of uveitis $(\mathrm{OR}=2.42[1.30 \ldots 4.52])$.

There was a statistically significant difference in the distribution of genotypes between the groups with and without uveitis: it was maintained with IL10 rs1800896 and revealed in the case of IRF5 rs3757385 polymorphism.

In the case of IL10 rs1800896 (see Fig. 2.7), heterozygous genotype with similar frequency was found in both groups, while the distribution of both homozygous genotypes was significantly different $\left(\mathrm{P}_{\chi}=1.08 \times 10^{-2} ; \mathrm{V}=0.30\right)$. The homozygous genotype $(G G)$ of the minor allele was the uveitis protective form with clinical significance: OR $0.15[0.04 \ldots 0.64]$ in the adaptive model and $0.31[0.08 \ldots 1.14]$ in the multiplicative model. In addition, in the multiplicative model, the risk level for homozygous genotype $(A A)$ of the major allele was clinically significant - OR 3.68 [1.45 ... 9.31].

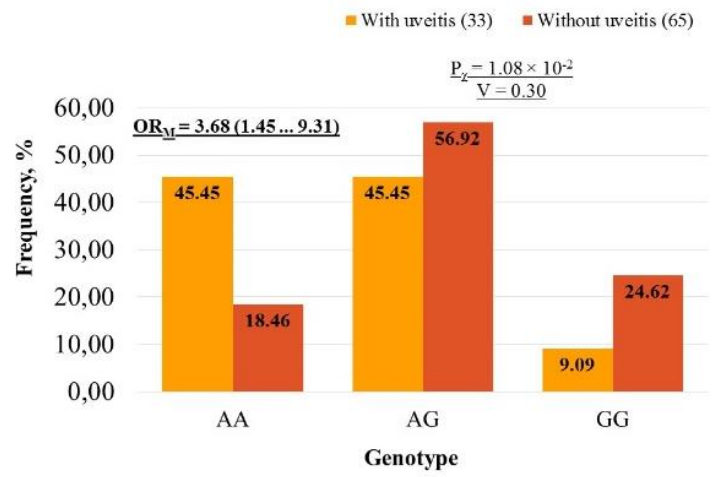

Figure 2.7. Distribution of $I L 10$ rs1800896 genotypes in the ankylosing spondylitis group with and without uveitis

Columns - frequency of the genotypes in the group, $\mathrm{P}_{\mathrm{x}}$ - statistical significance of the differences according to the contingency table, $\mathrm{V}$ - Cramer's $\mathrm{V}$ coefficient, $\mathrm{OR}$ - odds ratio for the risk genotype. 
IRF5 rs3757385 (see Fig. 2.8) had a similar frequency in both groups to the $T T$ genotype, with the other two genotypes having opposite distributions $\left(\mathrm{P}_{\chi}=2.96 \times 10^{-2} ; \mathrm{V}=0.27\right)$. The frequent genotypes were different: $G T$ was the genotype of uveitis risk $\left(\mathrm{OR}_{\mathrm{A}} 3.77[1.35 \ldots\right.$ 10.48] $), G G$ genotype was the protective form $\left(\mathrm{OR}_{\mathrm{M}} 0.33[0.13 \ldots 0.88]\right)$.

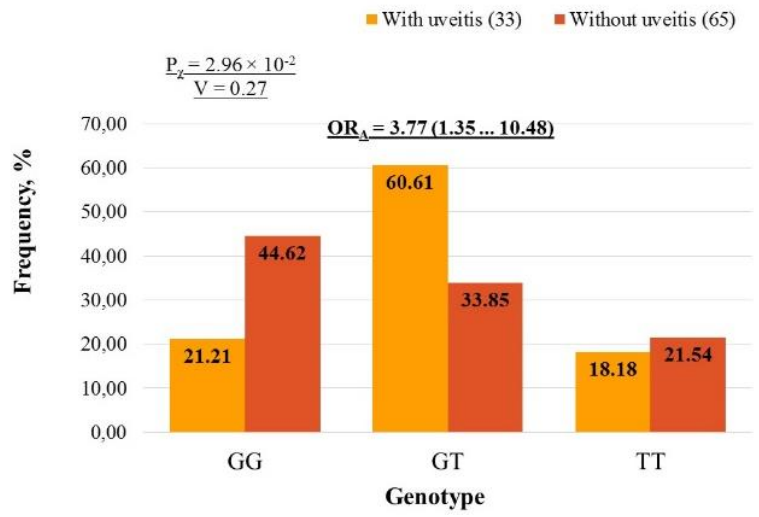

Figure 2.8. Distribution of IRF5 rs3757385 genotypes in the ankylosing spondylitis group with and without uveitis

Columns - frequency of the genotypes in the group, $\mathrm{P}_{\mathrm{x}}$ - statistical significance of the differences according to the contingency table, $\mathrm{V}$ - Cramer's V coefficient,

$\mathrm{OR}$ - odds ratio for the risk genotype.

The relationship of candidate gene polymorphisms of AS to peripheral arthritis

Analysis of the distribution of all SNPs alleles according to the presence of peripheral arthritis revealed that a statistically significant difference was observed in TGFB1 rs1800469.

When analysing the control and AS groups for TGF $\beta 1$ rs1800469, the minor allele was $C$ which differed from the analysis data of the AS group with and without peripheral arthritis $\left(\mathrm{P}_{\chi}=1.93 \times 10^{-2} ; \mathrm{V}=0.17\right)$ (see Fig. 2.9). Thus, the major $T$ allele of the control group was the risk allele for the development of 
peripheral arthritis in AS (OR $=1.98[1.11 \ldots 3.54])$, while the minor allele $C$ was with a protective effect $(\mathrm{OR}=0.50[0.28 \ldots 0.90])$.

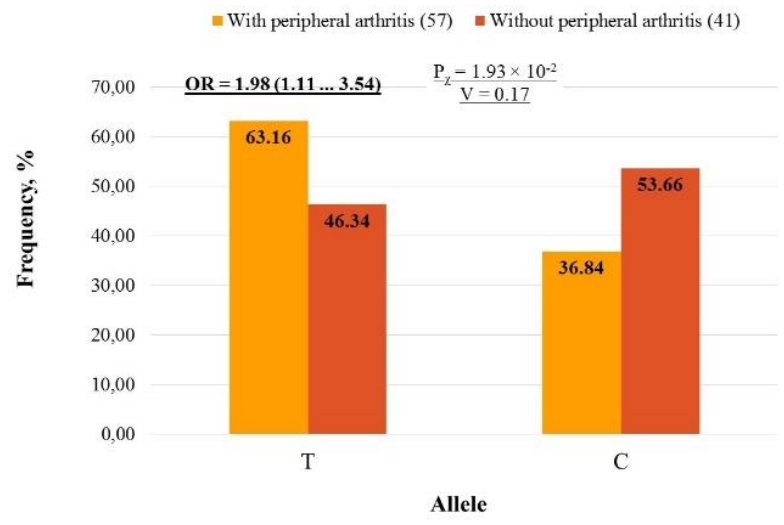

Figure 2.9. Distribution of $T G F \beta 1$ rs1800469 alleles in the ankylosing spondylitis group with and without peripheral arthritis

Columns - frequency of the alleles in the group, $\mathrm{P}_{\mathrm{x}}$ - statistical significance of the differences according to the contingency table, $\mathrm{V}$ - Cramer's V coefficient, $\mathrm{OR}$ - odds ratio for the risk allele.

A statistically significant difference between groups of AS with and without peripheral arthritis was observed in ERAP1 rs 10050860 (see Fig. 2.10). In this case, the homozygous form $(A A)$ of the minor allele was not detected in patients with peripheral arthritis but was found in two (4.88 \%) patients without this symptom $\left(\mathrm{P}_{\chi}=1.26 \times 10^{-2} ; \mathrm{V}=0.30\right)$. Thus, this genotype $(A A)$ could be considered (OR was not calculated, as it was not determined in one of the groups) as a protective form $\left(\mathrm{OR}_{\mathrm{A}}=0.48[0.38 \ldots 0.61] ; \mathrm{OR}_{\mathrm{M}}=0.41[0.32 \ldots 0.52]\right)$, but we could mark the heterozygous form $(G A)$ with $\mathrm{OR}_{\mathrm{A}}=3.68[1.24 \ldots 10.88]$ and $\mathrm{OR}_{\mathrm{M}}=3.89[1.32 \ldots 11.48]$ as a risk genotype. The homozygous form of the major allele also could be considered as a protective genotype with $\mathrm{OR}_{\mathrm{M}}=0.38$ $[0.14 \ldots 1.01]$. 


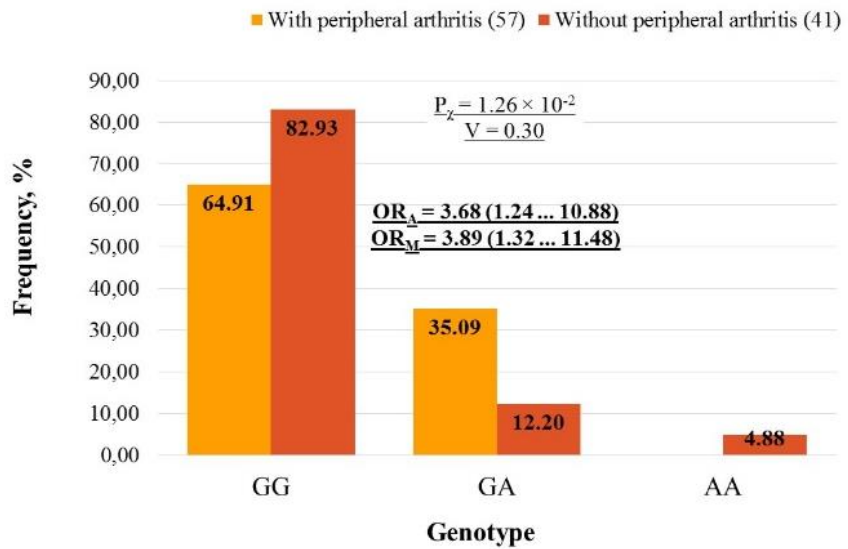

Figure 2.10. Distribution of ERAP1 rs10050860 genotypes in the ankylosing spondylitis group with and without peripheral arthritis

Columns - frequency of the genotypes in the group, $\mathrm{P}_{\mathrm{x}}$ - statistical significance of the differences according to the contingency table, $\mathrm{V}$ - Cramer's V coefficient, $\mathrm{OR}$ - odds ratio for the risk genotype.

The relationship of the polymorphisms of AS candidate genes with uveitis and peripheral arthritis

In analysis of the distribution of the alleles and the genotypes of all the SNPs following the existence of both manifestations, it was found that a statistically significant difference was observed for ERAP1 rs10050860 - the polymorphism which was not associated with the disease but had statistically significant link to the AS peripheral arthritis. The statistically significant difference for the distribution of alleles between the four subgroups in patients with and/or peripheral arthritis was not found, but it was found for the distribution of genotypes $\left(\mathrm{P}=3.21 \times 10^{-2} ; \mathrm{V}=0.27\right)$ (see Fig. 2.11). According to the results, the $A A$ genotype was identified only in patients without both manifestations. It was not found in the other three groups. In addition, $G A$ genotype was significantly more frequent in patients with peripheral arthritis alone compared to the rest of subgroups (including more than five times 
compared to the group without two analysed extraspinal manifestations (39.20 vs. $7.84 \%)$ ).

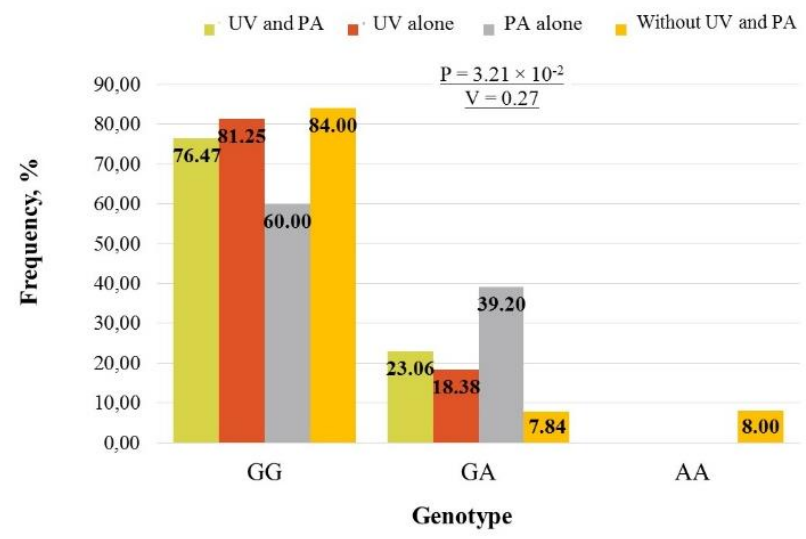

Figure 2.11. Distribution of ERAP1 rs10050860 genotypes in the ankylosing spondylitis group with uveitis (UV) and/or peripheral arthritis (PA)

Columns - frequency of the genotypes in the group, $\mathrm{P}_{\mathrm{x}}$ - statistical significance of the differences according to the contingency table, $\mathrm{V}$ - Cramer's V coefficient.

In the determination of the OR for each genotype, the homozygous form formed by the major allele was taken as a reference value. The subgroups of AS were analysed by the presence of uveitis and/or peripheral arthritis, and each subgroup was compared with the subgroup without both manifestations. The results indicated that $G A$ genotype in AS patients increased the chance of obtaining any of the analysed extraspinal manifestations: for uveitis and peripheral arthritis - $\mathrm{OR}_{M} 3.54$ [0.57 ... 22.03]; for uveitis alone - $\mathrm{OR}_{\mathrm{M}} 2.65$ [0.39 ... 18.00]; for peripheral arthritis $-\mathrm{OR}_{\mathrm{M}} 7.67$ [1.58 ... 37.12]. Thus, the results confirmed previously established data that ERAPI rs10050860 GA genotype was a particularly significant risk form for the manifestation of the AS peripheral arthritis.

The second locus where we found statistically significant difference between the four patient subgroups was in the distribution of the alleles of IL1O 
rs1800896 (see Fig. 2.12). In the subgroups of patients with peripheral arthritis alone and without both manifestations the distribution of alleles was similar to the control and AS groups, while in the other two subgroups of AS patients, uveitis and both extraspinal manifestations were less frequent in the case of the $G$ allele. In the control and AS group, the $G$ allele was seen averagely in $46.01 \%$, in the AS group with uveitis and peripheral arthritis - in $38.24 \%$ and in the AS group with uveitis alone - in $25.00 \%$. The differences obtained were statistically significant $\left(\mathrm{P}=2.73 \times 10^{-2} ; \mathrm{V}=0.22\right)$. Thus, these results reaffirmed the link of $I L 10$ rs $1800896 \mathrm{G}$ allele to the uveitis in AS patients.

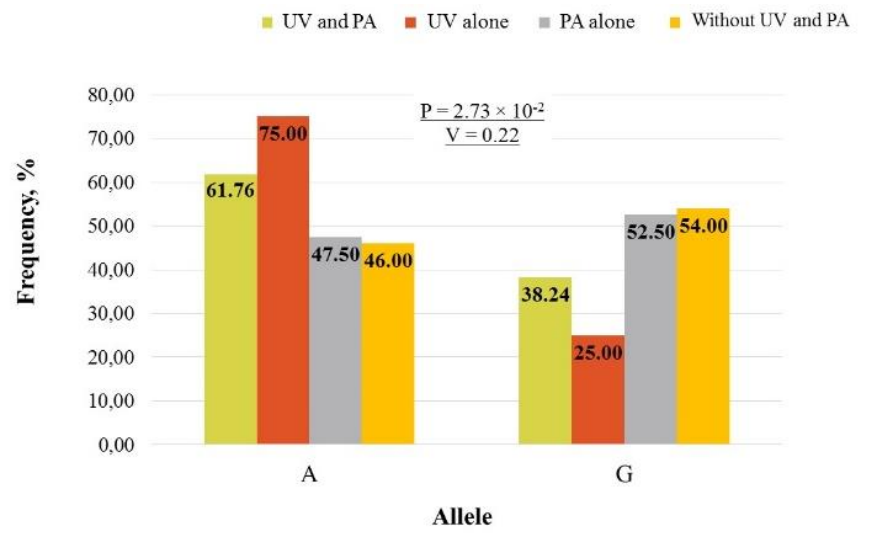

Figure 2.12. Distribution of $I L 10$ rs1800896 alleles in the ankylosing spondylitis group with uveitis (UV) and/or peripheral arthritis (PA)

Columns - frequency of the alleles in the group, $\mathrm{P}_{\mathrm{x}}$ - statistical significance of the differences according to the contingency table, V - Cramer's V coefficient.

\subsection{The link of multilocus haplotypes with ankylosing spondylitis and its extraspinal manifestations}

Combinations of haplotypes for both control and AS patient groups were formed according to three principles: 1) within a single gene when analysed at 
least three polymorphisms; 2) common signaling pathway protein genes; 3) combinations with SNPs associated with AS or its extraspinal manifestations. In the first group we identified haplotypes by analysing the ERAP1, IL23R and IRF5 genes. In the second group, we determined haplotypes by forming them between the TNF family signaling pathway protein genes (TNFA and CD40) and among genes encoding proteins of $\mathrm{TNF} \alpha, \mathrm{T}$ lymphocyte and dendritic cell interaction signaling pathways (IL10, TGF 1, IRF5 and PTPN22). In the third group the haplotypes made from TNFA rs1800629, CD40 rs4810485 and PTPN22 rs2476601 were analysed in the context of AS; in the case of AS uveitis - analysis of haplotypes formed by IRF5 rs3757385 and ILIO rs1800896; in the case of peripheral arthritis - analysis of haplotypes formed by ERAP1 rs10050860 and TGFB1 rs1800469; in the case of both extraspinal manifestations - analysis of haplotypes formed by IRF5 rs3757385, ERAP1 rs10050860, IL10 rs1800896 and TGFB1 rs1800469.

For the haplotypes created, we analysed the relationship with AS and its extraspinal manifestations, depending on the association of the SNPs.

\subsubsection{Haplotypes within the single gene}

When comparing the distribution of the haplotypes made from the SNPs of the single gene - ERAP1, IL23R or IRF5 - a statistically significant difference in the comparison of the control and AS groups was not observed. Analysis of these haplotypes in the context of extraspinal manifestations did not find any statistically significant difference of the ERAPI and IL23R genes.

In the individual analysis of the third gene, IRF5, a statistically significant association between the distribution of haplotypes and the presence of AS uveitis was found $\left(\mathrm{P}_{\chi}=2.97 \times 10^{-2} ; \mathrm{V}_{1}=0.22\right)$. While analysing these data (see Fig. 2.13), it was observed, firstly, that the most frequent haplotype GTT 
(rs10954213/ rs2004640/ rs3757385) was made from the minor alleles of these SNPs.

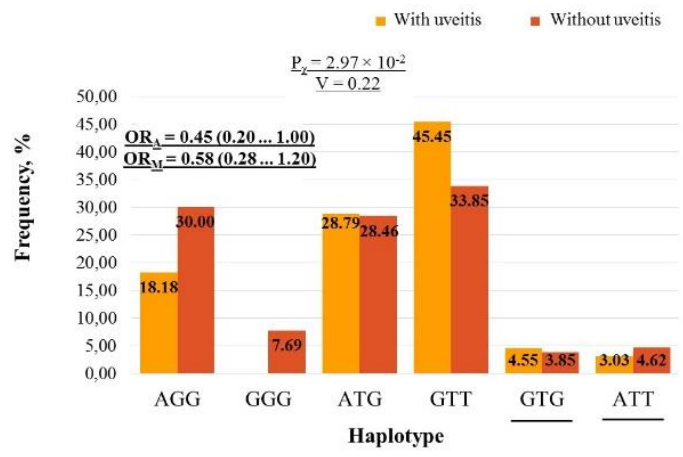

Figure 2.13. Distribution of the haplotypes of the IRF5 SNPs (rs10954213/ rs2004640/ rs3757385) in the ankylosing spondylitis group with and without uveitis

Columns - frequency of the haplotypes in the group, the rare haplotypes are underlined, $\mathrm{P}_{\mathrm{x}}$ - statistical significance of the differences according to the contingency table, $\mathrm{V}-$ Cramer's V coefficient, OR - odds ratio of the protective haplotype.

The $A G G$ haplotype made from the major alleles was seen approximetily in $20.00 \%$ of AS patients and controls, but the GTT haplotype was present in $37.76 \%$ and $38.31 \%$, respectively. Secondly, the haplotype GGG was determined only in patients without uveitis $(7.69 \%)$. The findings indicated that the particular haplotype was a protective form against uveitis. Another protective haplotype was $A G G$, which was observed in $18.18 \%$ of patients with uveitis and $30.00 \%$ without uveitis $\left(\mathrm{OR}_{\mathrm{M}} 0.58[0.28 \ldots 1.20] ; \mathrm{OR}_{\mathrm{A}} 0.45[0.20 \ldots 1.00]\right)$. Thirdly, the most frequent GTT haplotype was found to be the risk form for the development of uveitis - it was found in $45.45 \%$ of patients with uveitis and in

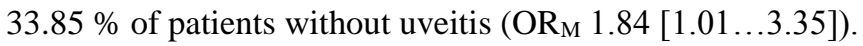

Analysis of IRF5 haplotypes in patients with and without peripheral arthritis as well as comparison of all AS four subgroups did not show any statitically significant difference. 


\subsubsection{Haplotypes within the genes coding the proteins of the TNF family signaling pathway}

A statistically significant difference $\left(\mathrm{P}_{\chi}=1.24 \times 10^{-5} ; \mathrm{V}=0.22\right)$ in the distribution of haplotypes formed by the SNPs of the TNFA and CD4O genes from the TNF signaling pathway was found during the analysis of the AS and control groups (see Fig. 2.14). In the data analysis it was found that the $G G$ haplotype made by the major alleles of both SNPs (TNFA rs1800629 and CD4O rs4810485) was also the most frequent haplotype in both patient and control groups. The frequency was similar in both groups: 63.27 vs. $61.69 \%$. Following the analysis of frequencies of the haplotypes and OR, it was determined that the haplotype $A G$ was disease-protective $\left(\mathrm{OR}_{\mathrm{M}}=0.34[0.19 \ldots 0.61] ; \mathrm{OR}_{\mathrm{A}}=0.38\right.$ $[0.21 \ldots 0.69])$, but the haplotype $G T-$ the risk form $\left(\mathrm{OR}_{\mathrm{M}}=2.29[1.45 \ldots 3.60]\right.$; $\left.\mathrm{OR}_{\mathrm{A}}=1.90[1.19 \ldots 3.02]\right)$.

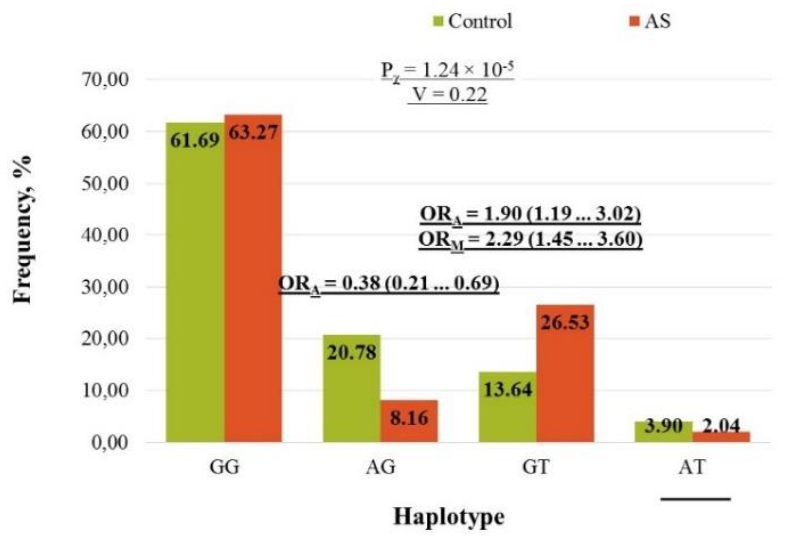

Figure 2.14. Distribution of the haplotypes of the TNFA rs1800629 and CD40 rs4810485 in the control and ankylosing spondylitis (AS) group Columns - frequency of the haplotypes in the group, the rare haplotypes are underlined, $\mathrm{P}_{\mathrm{x}}$ - statistical significance of the differences according to the contingency table, $\mathrm{V}-$ Cramer's V coefficient, OR - odds ratio. 
No statistically significant differences were found $\left(\mathrm{P}_{\chi}>0.05\right)$ in the analysis of the subgroups of uveitis and/or peripheral arthritis mentioned above.

\subsubsection{Haplotypes formed by the SNPs of the genes encoding the signaling pathway of interaction of TNF $\alpha$, T lymphocytes and dendritic cells}

Analysis of polymorphisms localised in the genes or associated with the genes encoding proteins of the signaling pathway of the interaction between TNF $\alpha$, T lymphocytes and dendritic cells - IL10, TGF 1 1, IRF5 and PTPN22, revealed 63 haplotypes out of 128 haplotypes which were calculated theoretically. When selecting rare haplotypes (frequency of less than $5.00 \%$ ), five haplotypes remained, which covered $25.51 \%$ (AS) and $36.04 \%$ (control) of the samples. Since it was less than one-third of the patient samples, it was decided to change the loci included in the haplotypes. Regarding the aspect that proteins encoded by ILIO and TGF 1 share a common signaling pathway, combinations of haplotypes using these SNPs were formed. In addition, the SNP of IL10 was linked to uveitis and $T G F \beta 1$ rs1800469 was associated with peripheral arthritis.

While analysing the distribution of haplotypes formed by IL10 rs 1800896 and TGF $\beta 1$ rs1800469 and rs1800470 in AS and control gropus, eight possible haplotypes were identified, two of which were rare. The most frequent haplotype in the AS group was ATC (IL1O rs1800896/ TGFB1 rs1800469 / TGFB1 rs1800470) with the major alleles in the two loci, and in the control group - ACT. The most frequent haplotype used as reference haplotype was $A C T$, which detected in $20.41 \%$ of AS patients and $24.03 \%$ of controls. Comparison of the distribution of haplotypes did not find statistically significant difference. 


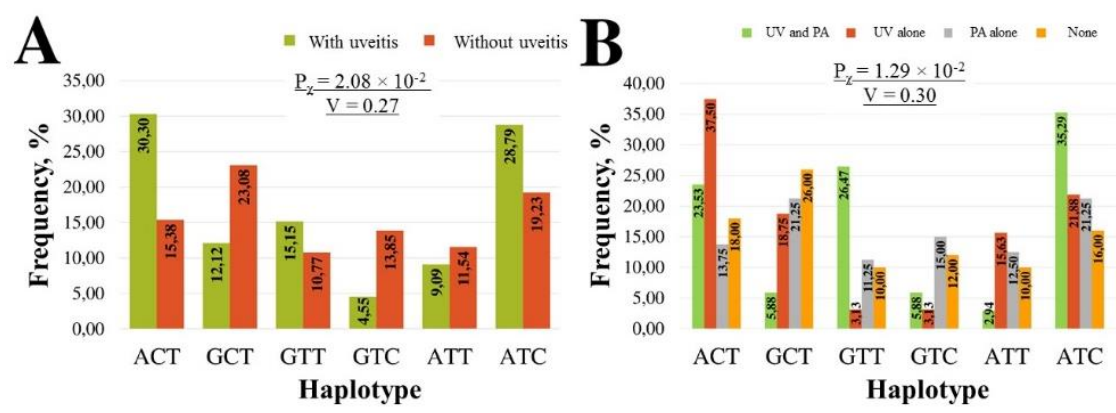

Figure 2.15. Distribution of the haplotypes (without rare forms) of the IL10 (rs1800896) and TGFß1 (rs1800469 and rs1800470) in the ankylosing spondylitis group (A) with and without uveitis (UV) and (B) with uveitis and/or peripheral arthritis (PA)

Columns - frequency of the haplotypes in the group, $\mathrm{P}_{\mathrm{x}}$ - statistical significance of the differences according to the contingency table, $\mathrm{V}$ - Cramer's V coefficient.

In the analysis of the mentioned distribution of the haplotypes in the uveitis and peripheral arthritis AS subgroups it was no longer so similar. A statistically significant difference was found in the analysis of two groups (see Fig. 2.15A) - with uveitis and without uveitis $\left(\mathrm{P}_{\chi}=2.08 \times 10^{-2}(\mathrm{~V}=0.27)\right.$ without rare haplotypes or $\mathrm{P}_{\chi}=1.29 \times 10^{-2}(\mathrm{~V}=0.30)$ with rare haplotypes $)$, as well as in the analysis of all four subgroups (see Fig. 2.15B): the subgroup with uveitis, the subgroup with peripheral arthritis, the subgroup with both manifestations and the group without these manifestations $\left(\mathrm{P}_{\chi}=1.90 \times 10^{-2}(\mathrm{~V}=0.22)\right.$ without rare haplotypes or $\mathrm{P}_{\chi}=2.18 \times 10^{-2}(\mathrm{~V}=0.25)$ with rare haplotypes $)$.

In the analysis of the frequency of haplotypes in the subgroups of AS extraspinal manifestations it was found that three haplotypes out of four with the minor allele $G$ of IL1O SNP were significantly less common in patients with uveitis in comparison with patients without uveitis. Haplotypes GCC and GTC were absent or very rare in patients with uveitis, but haplotype $G C T$ was more than three times more frequent in patients with uveitis than in patients with uveitis and peripheral arthritis. Thus, haplotypes GCC and GTC protect against 
uveitis in AS, but haplotype $G C T$ is the protective form against peripheral arthritis in patients with uveitis $\left(\mathrm{OR}_{\mathrm{M}}=0.27[0.05 \ldots 1.45]\right)$.

Analysis of these three haplotypes for uveitis only determined that all three were protective forms against uveitis with OR ranging from 0.17 to 0.46 .

In the position of the fourth haplotype with the allele $G$ in the ILIO rs 1800896 polymorphism or in the case of the haplotype GTT the situation was different: its frequency was significantly higher in the group with peripheral arthritis and uveitis compared with other three groups -26.47 vs. $3.13 \%$ in the group with uveitis alone $\left(\mathrm{OR}_{\mathrm{M}}=11.16[1.32 \ldots 94.11]\right)$; in the group with peripheral arthritis alone $-11.25 \%\left(\mathrm{OR}_{\mathrm{M}}=2.84[1.01 \ldots 7.96]\right)$; in the group without both manifestations $-10.00 \%\left(\mathrm{OR}_{\mathrm{M}}=3.24[0.98 \ldots 10.73]\right)$. Thus, the data were obtained that the particular haplotype was a form of risk for the development of both AS extraspinal manifestations as well as for the development of second manifestation for patients with the presence of uveitis or peripheral arthritis.

Haplotype GTT for uveitis alone did not exhibit a markedly high OR, indicating that it was important for both manifestations.

The second risk haplotype for extraspinal manifestations was $A C T$, which was twice as common in patients with uveitis compared to patients without uveitis (30.30 vs. $15.38 \%$ ), serving as a risk form for the development of uveitis in AS patients $\left(\mathrm{OR}_{\mathrm{M}}=2.39[1.18 \ldots 4.86]\right)$. In the analysis of four subgroups (see Fig. 3.15B) it was found that the difference in the frequency of haplotypes between patients with uveitis alone or peripheral arthritis alone and patients with uveitis and peripheral arthritis was $10-12 \%$, but with opposite tendencies. The OR for peripheral arthritis in patients with uveitis was 0.51 [0.18 ... 1.49] and for uveitis in patients with peripheral arthritis was 1.93 [0.70 ... 5.33]. Thus, the particular haplotype reduced the chance of development of peripheral arthritis in patients with uveitis and increased the risk of uveitis in peripheral arthritis patients. 


\subsubsection{Haplotypes of the linked SNPs}

Three SNPs were found to be associated with the disease as a whole: $T N F A$ rs1800629 with the risk allele $G, C D 40$ rs4810485 with the risk allele $T$ and PTPN22 rs2476601 with the risk allele $T$. Thus, based on individual SNP association analysis results, haplotype GTT (TNFA rs1800629, CD40 rs4810485, PTPN22 rs2476601) should be at high risk for the development of AS.

When analysing the data, it was determined that in the control group all eight possible haplotypes were found, whereas in the AS group - only seven. When evaluating both groups, only two could be considered as rare haplotypes. In both groups, haplotype $G G C$ was the most frequently detected form with frequencies of $40.82 \%$ in the AS group and $48.38 \%$ in the control group (see Fig. 2.16). The distribution of the six statistically analysed haplotypes in the control and AS groups was statistically significantly different $\left(\mathrm{P}_{\chi}=3.87 \times 10^{-6}\right)$.

When analysing distribution of haplotypes (see Fig. 2.16) and the OR test results, it was found that three forms of haplotypes were protective of AS and threee forms were risk haplotypes. The highest risk level was for the predicted haplotype GTT, which contained the risk alleles of all three loci and was found in $9.18 \%$ of AS patients, but only in $2.92 \%$ of the control group. This haplotype increases the possibility of developing AS more than 3.5 times $\left(\mathrm{OR}_{\mathrm{A}}=3.73\right.$ $[1.60 \ldots 8.67]$ and $\mathrm{OR}_{\mathrm{M}}=3.36[1.48 \ldots$ 7.64]). The other two haplotypes that

were found to be at increased risk but not of clinical significance were GTC (17.35 vs. $10.71 \%)$ and $G G T$ (22.45 vs. $13.31 \%)$. After analysis of haplotypes loci it was detected that all three risk forms had the risk allele $G$ at the TNFA rs1800629 locus. 


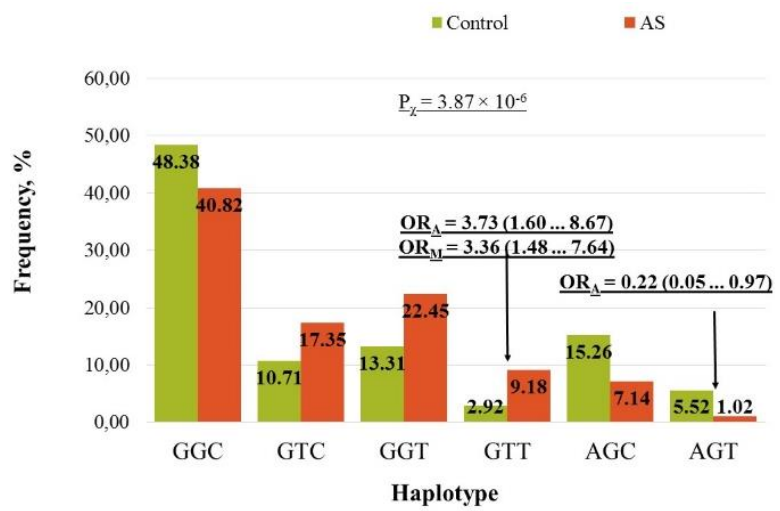

Figure 2.16. Distribution of the haplotypes (without rare forms) of the TNFA rs1800629, CD40 rs4810485, PTPN22 rs2476601 in the control and the ankylosing spondylitis (AS) groups

Columns - frequency of the haplotypes in the group, $P_{x}-$ statistical significance of the differences according to the contingency table, $\mathrm{V}$ - Cramer's V coefficient.

When looking at haplotypes protecting against AS development: $G G C$, $A G C$ and $A G T$, it was found that the $C D 40$ rs 4810485 locus had protective allele $G$ in all three cases. The highest protective level had the haplotype $A G T$, which reduced the likelihood to develop the disease 4.5-5.6 times $\left(\mathrm{OR}_{\mathrm{A}}=0.22\right.$ $\left[0.05 \ldots\right.$ 0.97], $\left.\mathrm{OR}_{\mathrm{M}}=0.18[0.04 \ldots 0.77]\right)$. For the other two haplotypes the OR ranged from 0.43 to 0.74 .

A statistically significant association with uveitis was found for two SNPs: IRF5 rs3757385 with a potential (genotype only) risk allele $T$ and ILIO rs 1800896 with the risk allele $A$. Upon analysis of all four possible haplotypes, the most frequent haplotype differed in AS group with uveitis from the group without uveitis (see Fig. 2.17): the most frequent haplotype in the AS group with uveitis was $T A$, but in the group without uveitis - $G G$ haplotype $\left(\mathrm{P}_{\chi}=2.20 \times 10^{-2}\right)$. Haplotype $T A$ had a high but not clinically significant $\mathrm{OR}$ $\left(\mathrm{OR}_{\mathrm{A}}=2.91[1.32 \ldots 6.41], \mathrm{OR}_{\mathrm{M}}=2.37[1.24 \ldots 4.52]\right)$. The second risk haplotype was $G A$. The highest protective effect was found for the $G G$ haplotype $\left(\mathrm{OR}_{\mathrm{M}}=0.52[0.26 \ldots 1.02]\right)$. 


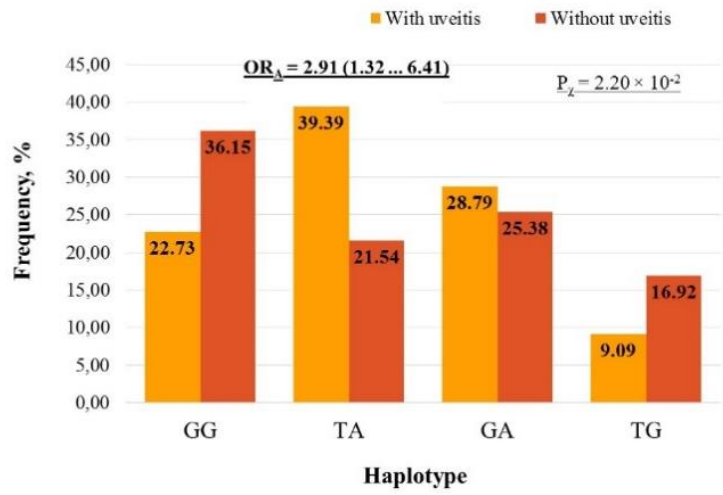

Figure 2.17. Distribution of the haplotypes (without rare forms) of the IRF5 rs3757385 un $I L 10$ rs1800896 in the ankylosing spondylitis group with and without uveitis

Columns - frequency of the haplotypes in the group, $\mathrm{P}_{\mathrm{x}}$ - statistical significance of the differences according to the contingency table, $\mathrm{V}$ - Cramer's V coefficient.

Statistically significant association was found with peripheral arthritis for two SNPs: ERAP1 rs10050860 with the risk genotype GA (both homozygous genotypes were protective) and $T G F \beta 1$ rs 1800469 with the risk alle $T$. In the analysis of the distribution of the haplotypes formed by these two SNPs in the group with and without peripheral arthritis, it was found that the frequency differences between the groups were not statistically significant $\left(\mathrm{P}_{\chi}=0.07\right)$. This could be explained by the fact that in the case of ERAPI rs10050860, the significance was on the level of genotypes, not alleles and the $G A$ genotype was a form of risk.

When combining uveitis and peripheral arthritis-associated SNPs loci in a single haplotype, IRF5 rs3757385, ERAP1 rs10050860, IL10 rs1800896 and TGF 1 rs 1800469 analysis data were used for detection of relationship with AS uveitis and/or peripheral arthritis. Analysis of the distribution of the frequency of haplotypes in four groups of AS patients revealed that the frequency difference 
was not statistically significant $\left(\mathrm{P}_{\chi}=0.16\right)$. Thus, all four loci were unrelated to uveitis and/or peripheral arthritis.

\subsection{The link of the ankylosing spondylitis candidate gene polymorphisms to the disease biomarkers}

In the study, the association of the alleles and/or genotypes of the selected candidate gene polymorphisms were analysed with the disease assessment biomarkers chosen according to the data of scientific publications and current issues in clinical work: the age at the onset of first AS symptoms, the assessment of spinal structural damage (mSASSS) and the efficacy of the first treatment year with bDMARDs (TNF $\alpha$ inhibitors) assessed by BASDAI (BASDAI $<4$ or reduction of BASDAI value by two units from baseline without worsening during the year), the transition of the disease to the inactive form (BASDAI $<4$ ), and the trends of the disease activity changes.

\subsubsection{The age at the onset of first ankylosing spondylitis symptoms}

In the study, it was analysed whether the candidate gene polymorphisms affect the age at the onset of first AS symptoms. The median age at the onset of first symptoms in 98 AS patients was $26.33 \pm 6.82$ (CI $95 \% 24.96$... 27.69) years with a range from 18 to 45 years. When comparing genotypes to the age of the onset of first AS symptoms, it was found that none of the 15 SNPs had a statistically significant effect on this aspect $(\mathrm{P}>0.05)$. 


\subsubsection{The assessment of spinal structural damage (mSASSS)}

Patients had a mean mSASSS of $23.41 \pm 21.32$ (CI $95 \% 18.95 \ldots 27.88$ ) with a range from 0 to 35 . The value of mSASSS at a given time was dependent on the disease duration. Patients had a mean disease duration of $13.79 \pm 8.29$ (CI $95 \% 12.12 \ldots 15.45$ ) years with an interval of 1 to 35 . In addition, it was determined that mSASSS had a moderately significant $(\rho=0.49)$ correlation with BASFI $\left(P_{r}=9.98 \times 10^{-7}\right)$ and a significant $(\rho=0.77)$ correlation with BASMI $\left(\mathrm{P}_{\mathrm{r}}=6.23 \times 10^{-19}\right)$.

As a result of the analysis, it was found a statistically significant $\left(P_{r}=9.00 \times 10^{-6}\right)$ moderate $(\rho=0.45)$ correlation between the radiological data (mSASSS) and the duration of the disease. Using simple linear regression, it was determined that $15.21 \%\left(\mathrm{R}^{2}=0.15\right)$ of the mSASSS value was based on the disease duration with the equation: $\mathrm{mSASSS}=9.12+1.04 \times \mathrm{SI}$, where SI is the duration of the disease $\left(\mathrm{P}_{\mathrm{R}}=1.45 \times 10^{-4}\right)$. Thus, it was concluded that mSASSS increased by 1.04 points as the disease duration increased by one year.

However, regression analysis showed that there was another factor that affected mSASSS. It was assumed that one of such factors could be a genetic factor. In order to determine the potential effects of genotypes, when conducting the analysis, two aspects were considered: 1) duration of the disease; 2) variability of mSASSS over time. Thus, multiple regression analysis was used to determine whether the genotype also affects the mSASSS value. The effects of the genotype could be judged if: 1 ) the regression model $-\operatorname{mSASSS}=\mathrm{B}+$ SI $\times x_{1}+$ Genotype $\times x_{2}\left(x_{1}\right.$ and $x_{2}$ are regression coefficients $)-$ was statistically significant; 2) the statistical significance $\mathrm{P}_{\mathrm{RF}}$ of the genotype or the individual factor was less than 0.05 . 
In addition, by knowing the volume of the effect of the disease duration on mSASSS ( $15.21 \%$ or 0.15 ), it was possible to calculate the preliminary effects of the genotype.

In cases where statistically significant effects of the genotypes of the candidate gene SNPs were identified, analysis of non-parametric indices was conducted to determine the difference of mSASSS between genotypes in patients with the AS duration up to 15 years (inclusive) and patients with the AS duration of more than 15 years.

In the processing of all candidate gene polymorphisms using regression analysis, a statistically significant regression equation was found only for one SNP - IRF5 rs 10954213 which had a statistically significant effect on mSASSS $\left(\mathrm{P}_{\mathrm{RF}}=2.28 \times 10^{-2}\right)$. In this case the explainable part of mSASSS increased to $20.14 \%$, an increase by $4.93 \%$, which could be explained by the genetic factor. The final equation of this regression model was mSASSS $=-4.75+1.11 \times \mathrm{SI}+$ $6.59 \times$ Genotype, with genotype values of 1,2 and 3 for genotypes $A A, A G, G G$ ( $A A$ was the most frequent genotype), respectively. Thus, we could notice that mSASSS was higher in the case of homozygous genotype of the minor $G$ allele.

When categorising all patients by the genotypes of IRF5 rs 10954213 (see Fig. 2.18), the effect of the disease duration on mSASSS was found to be significantly higher in the case of the minor allele $G G$ genotype than in the presence of the major allele genotype $A A\left(\mathrm{R}^{2}\right.$ was 40.49 vs. $0.56 \%$; in the case of $A G$ genotype $-\mathrm{R}^{2}=20.66 \%$ ).

For $A A$ genotype of the major allele, the regression model was not statistically significant, but for the other two genotypes statistically significant data were obtained $\left(\mathrm{P}_{\mathrm{R}}<0.02\right)$. For $G G$ genotype, each subsequent year of the disease in the $40.49 \%$ of the cases increased the mSASSS value by 1.72 points, but in case of the $A G$ genotype - by 1.37 points. For the homozygous genotype of the major allele, this increase would be only 0.15 points, if the regression model had been significant. 


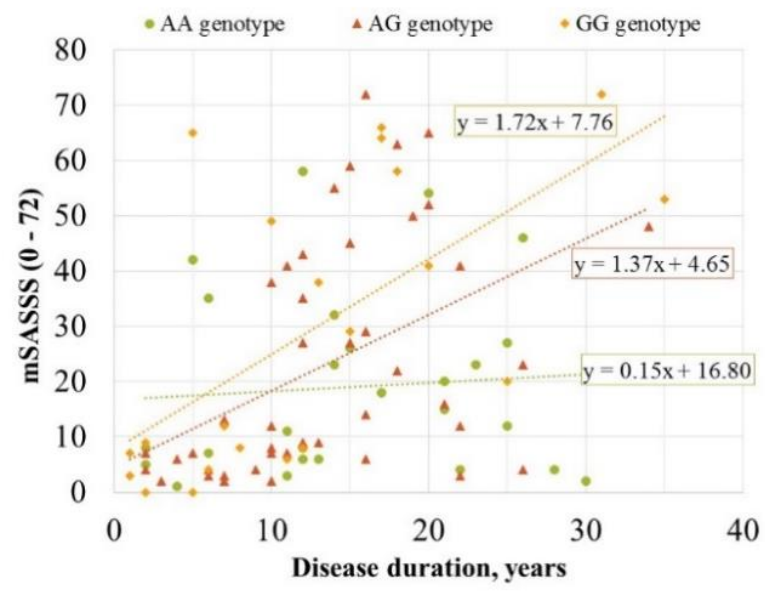

Figure 2.18. Impact of the disease duration to the mSASSS value of the ankylosing spondylitis patients with different genotypes of IRF5 rs10954213

When dividing patients by the disease duration and the mSASSS according to the genotype of IRF5 rs10954213, it was determined that mSASSS (median) did not differ statistically significantly between the groups $\left(\mathrm{P}_{\mathrm{KV}}=0.95\right)$ in patients with disease duration up to 15 years (inclusive). In patients with the disease duration above 15 years, mSASSS was statistically different $\left(\mathrm{P}_{\mathrm{KV}}=1.53 \times 10^{-2}\right)$. Both the median and the mean mSASSS values were greater in patients with $G G$ genotype.

Thus, in the analysis of IRF5 rs10954213, it was noticed that the minor allele (in both homozygous and heterozygous genotypes) was a risk form for a pronounced increase in mSASSS, along with an extension of the disease period for each year. 


\subsubsection{The relationship and possible impact of the candidate gene polymorphisms of ankylosing spondylitis on the efficacy of the treatment with TNF $\alpha$ inhibitors}

A subgroup was created from the 98 AS patient group who were taking one of the TNFa inhibitors during the enrollment in the study or started this treatment in the period until March 2019. A total of 54 (55.10\%) patients were selected. In these patients the efficacy of the treatment with TNF $\alpha$ inhibitors was assessed during the first year of its administration by analysing BASDAI and its changes in dynamics.

Patients were divided into two groups according to the efficacy of the treatment: positive (BASDAI $<4$ or BASDAI reduction by two units from baseline without deterioration during the year) and negative (BASDAI decrease by less than two units from baseline at the end of the assessment period) as well as according to the disease activity after first year of the treatment: active $(\mathrm{BASDAI} \geq 4)$ or inactive (BASDAI $<4$ ) disease. The distribution of the alleles and genotypes of the candidate gene polymorphisms was determined between the established groups.

Among first-year treatment users of TNF $\alpha$ inhibitors, 41 (75.93\%) patients demonstrated therapeutic efficacy, and $13(24.07 \%)$ did not have a defined therapeutic effect. After one year of treatment, disease activity remained in $21(38.89 \%)$ patients, and inactive disease was observed in $33(61.11 \%)$ patients.

Following the data obtained, it was found that the tested candidate gene SNPs were not statistically significantly related to the defined efficacy of the treatment with $\mathrm{TNF} \alpha$ inhibitors.

In the analysis of the distribution of the alleles and genotypes in the groups depending on BASDAI following the first year of the treatment with 
TNF $\alpha$ inhibitors, it was found that the distribution of the alleles or genotypes of three gene SNPs (TNFA rs1800629, ERAPI rs10050860 and IL10 rs1800896) was statistically significantly related to the disease activity.

In the case of TNFA rs1800629, none of the patients with active disease and treated with the TNF $\alpha$ inhibitors had a minor allele $A$, but it was detected in $9.09 \%$ of patients with inactive disease $\left(\mathrm{P}_{\chi}=4.44 \times 10^{-2}(\mathrm{~V}=0.19)\right)$. The OR could not be calculated because one of the alleles was not present in both groups.

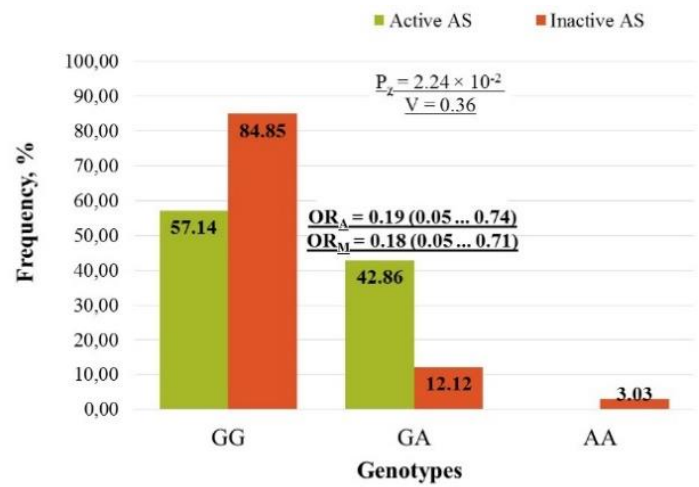

Figure 2.19. Distribution of the genotypes of the ERAP1 rs10050860 in the ankylosing spondylitis (AS) group according to the efficacy of the first year treatment with TNF $\alpha$ inhibitors

Columns - frequency of the genotypes in the group, $\mathrm{P}_{\mathrm{x}}$ - statistical significance of the differences according to the contingency table, V - Cramer's V coefficient, OR - odds ratio.

ERAP1 rs10050860 GG genotype was identified in $84.85 \%$ of patients with inactive disease and in $57.14 \%$ of patients with active disease $\left(\mathrm{P}_{\chi}=2.24 \times 10^{-2}(\mathrm{~V}=0.36)\right.$; see Fig. 2.19.). This genotype contributed to the transition of the disease into an inactive form during the first year of the treatment with TNF $\alpha$ inhibtors $\left(\mathrm{OR}_{\mathrm{M}}=4.20[1.16 \ldots 15.19]\right)$. Genotype $G A$ was a form contributing to the maintenance of the disease activity $\left(\mathrm{OR}_{\mathrm{A}}=0.19\right.$ $\left.[0.05 \ldots 0.74] ; \mathrm{OR}_{\mathrm{M}}=0.18[0.05 \ldots 0.71]\right)$. 
The relationship of ILIO rs1800896 was found based on the distribution of the genotypes $\left(\mathrm{P}_{\chi}=2.10 \times 10^{-2}(\mathrm{~V}=0.37)\right.$; see Fig. 2.20). Genotype $G A$ contributed to the maintenance of the disease activity during the treatment with $\mathrm{TNF} \alpha$ inhibitors $\left(\mathrm{OR}_{\mathrm{A}}=0.47[0.13 \ldots 1.69] ; \mathrm{OR}_{\mathrm{M}}=0.25[0.08 \ldots 0.88]\right)$.

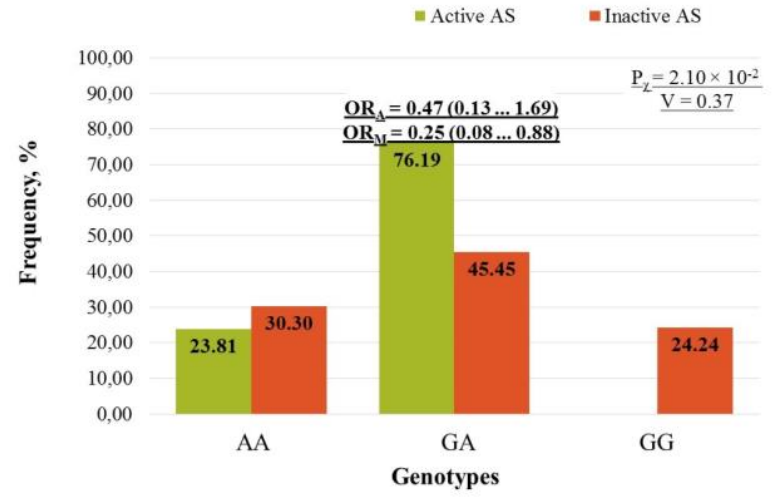

Figure 2.20. Distribution of the genotypes of the IL10 rs1800896 in the ankylosing spondylitis (AS) group according to the efficacy of the first year treatment with $\mathrm{TNF} \alpha$ inhibitors

Columns - frequency of the genotypes in the group, $\mathrm{P}_{\mathrm{x}}$ - statistical significance of the differences according to the contingency table, V - Cramer's V coefficient, OR - odds ratio.

In addition to the results of the specific treatment, the effects of the genotype on changes in BASDAI after twelve months of the treatment with $\mathrm{TNF} \alpha$ inhibitors were analysed in comparison with the baseline data. On average, BASDAI changed by $2.87 \pm 1.77$ units $(0.48 \pm 0.31$ decimals $)$ from baseline (BASDAI at 12 months/BASDAI before starting the treatment with $\mathrm{TNF} \alpha$ inhibitors) ranging from -2.20 to 6.40 units or -0.41 to 0.96 decimals.

In the analysis of the results of changes in BASDAI, it was found that the mean change in BASDAI at 12 months in the case of the homozygous genotype $T T$ of the minor allele in IRF5 rs3757385 (see Fig. 3.21) was statistically significantly higher than for the other two genotypes: $3.33 \pm 1.52$ units vs. $1.68 \pm 1.37$ and $3.01 \pm 1.91$ units for $G G$ and $T G$ genotypes, respectively 
$\left(\mathrm{P}_{\mathrm{F}}=4.96 \times 10^{-2} ; \eta=0.32\right)$. When combining the analysis of the genotypes with the minor alelle ( $T G$ and $T T$ ), the mean value of $3.14 \pm 1.75$ was detected (44 patients) and in comparison to the $G G$ genotype group, data with a more significant statistical difference were obtained $\left(\mathrm{P}_{\mathrm{F}}=1.69 \times 10^{-2}\right)$, without changing the coefficient eta. Thus, it was determined that the $T$ allele of IRF5 rs3757385 increased the change in BASDAI during the 12-month period.

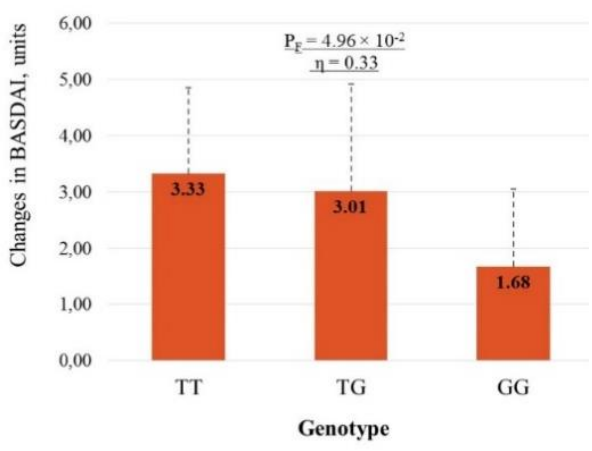

Figure 2.21. Change in BASDAI after the first year of treatment with TNF $\alpha$ inhibitors depending on the genotypes of IRF5 rs3757385 Columns - mean parameter with standard deviation, $\mathrm{P}_{\mathrm{F}}-$ the statistical significance of ANOVA test, $\eta$ - eta correlation coefficient. 


\section{Discussion}

Study data characterise the AS group, indicating significant impact of the disease on quality of life - high disease activity in most patients (BASDAI $\geq 4$ in $65.31 \%$ of patients; ASDAS $_{\mathrm{CRP}} \geq 1.3-82.65 \%$ ) with disabilities in daily activities (BASFI $3.72 \pm 2.69$ ) and restriction of spinal movements (BASMI $3.89 \pm 2.60)$. In the study, the age at onset of first symptoms is consistent with scientific publications, with $80 \%$ of AS patients showing their first symptoms before age 30 (Feldtkeller et al., 2000). Analysing the degree of morning stiffness, back pain and fatigue caused by the disease, the average values of these self-assessments were above five $(5.46 \pm 3.16,5.55 \pm 2.94$ and $5.34 \pm 2.50$, respectively). According to scientific publications pain, stiffness and fatigue are the most common symptoms reported by AS patients (Schneeberger et al., 2014).

When describing the AS patient profile, it should be noted that the majority of patients being under the supervision of the Centre of Rheumatology has active and advanced disease.

The majority of patients in the AS group were male (91.84\%). Although it is currently considered that the male-female ratio among AS patients is 2:1, the patient composition of our study is more consistent with the data of previous decades when it was thought to be 10 to 1 (Rusman et al., 2018; Taurog et al., 2016). One of the explanations is the fact that structural changes in the sacroiliac joints in females visualised radiographically develop later in comparison with males; therefore, there is diagnostic delay in female patients (Rusman et al., 2018).

In the study more than half of the patients experienced peripheral arthritis $(58.16 \%)$ and approximately one-third of the patients had uveitis (33.67\%) which is consistent with publication data on the frequency of AS extraspinal manifestations (de Winter et al., 2016). 
While analysing the profile of AS patients with uveitis, it was found that patients with uveitis had a longer disease duration compared to the subgroup without uveitis (17 vs. 12 years). The data of scientific publications show that the prevalence of uveitis in $\mathrm{SpA}$ increases linearly with disease duration up to 20 years, but after this time the prevalence seems to reach plateau, therefore, indicating that after 20 years of the disease the future risk of the development of the first episode of uveitis is very low (Zeboulon et al., 2008). This aspect is important considering the potential risk of the development of uveitis in AS patients after enrollment in the study. In contrast, a recent publication compiling data from the Belgian Nationwide Axial SpA cohort indicates that the risk of acute anterior uveitis increases by $30 \%$ after every ten years of the disease explaining this with the potential risk of cumulative inflammation (Varkas et al., 2018).

The study showed lower disease activity $\left(\mathrm{ASDAS}_{\mathrm{CRP}}\right)$ in patients with uveitis compared to patients without uveitis. Perhaps it can be explained by pronounced clinical picture of uveitis which requires patients to seek urgent medical help in case of its exacerbation and to pay more attention to the treatment of the disease. Publications show that AS patients with uveitis have higher disease activity (BASDAI) and more prominent functional disability (BASFI) (Raffeiner et al., 2014).

Patients with peripheral arthritis had a higher level of CRP compared to patients without this manifestation (21.86 vs. $8.85 \mathrm{mg} / \mathrm{L})$. CRP is a prognostic factor for the progression of structural damage in AS, analysing mainly spinal changes (Braun et al., 2016). It should be noted that individual studies have shown fewer structural spinal changes in patients with peripheral arthritis compared to patients without peripheral arthritis (Kim et al., 2014). These results indicate the need to assess the prognostic importance of CRP for the evaluation of structural damage in AS depending on the phenotype of the disease. The second statistically significant difference in comparing patients with and without 
peripheral arthritis was found in the value of self-assessment of joint pain which was higher in patients with peripheral arthritis (4.54 vs 1.83 ). In this case, it is important to note that joint pain can be caused by both factors - inflammation and structural changes induced by inflammation or deformities, therefore, partly explaining the absence of difference in the evaluation of disease activity in patients with and without peripheral arthritis.

During the analysis of subgroups of patients with and without uveitis and subgroups with and without peripheral arthritis, no association was found between the frequency of uveitis and peripheral arthritis. Data analysis of the Korean SpA registry describes correlation between uveitis and hip involvement (Kook et al., 2019). When comparing the data of the studies, it is important to consider whether the presence of arthritis in this localisation is classified as an axial or peripheral AS.

In the study, a statistically significant difference was not found in structural spinal damage (mSASSS), when categorising patients according to the presence of uveitis or peripheral arthritis. Similar data were obtained in an analysis of the data of the Korean SpA registry where no relationship was established between the presence of AS uveitis and the progression of mSASSS in a five-year assessment (Kook et al., 2019). Meanwhile, the data from this registry indicate that AS patients with peripheral arthritis have lower mSASSS compared to patients without peripheral arthritis in a 2.7-year observation (Kim et al., 2014), which is inconsistent with the current study data.

In four groups, depending on the presence of peripheral arthritis and/or uveitis, data on a statistically significant difference in four parameters were obtained: duration of the disease, activity assessment based on CRP as well as ASDAS $_{\mathrm{CRP}}$ and self-assessment of joint pain, where the highest mean values were in the group with uveitis and peripheral arthritis, but the lowest in the group with uveitis. These results demonstrate the importance of cumulative inflammation in 
the course of the disease, as well as the effect of its caused structural damage in the assessment of pain level in peripheral arthritis.

At present, genetic studies of various AS populations are ongoing, including detection of non-HLA candidate genes (Brown et al., 2016; Schiotis et al., 2013). However, the results of these studies still do not provide a complete answer on the etiopathogenesis of AS, thus highlighting the need for further investigation.

In the context of the evaluation of AS and genetic aspects in our study, analysing alleles, genotypes and haplotypes of eight gene polymorphisms, three important questions were raised about: 1) the association of candidate gene polymorphisms with the disease itself; 2) the relationship of polymorphisms of candidate genes with a variety of phenotypic manifestations, including the risk of developing uveitis and/or peripheral arthritis as the most common extraspinal manifestations; 3) the possibility of using candidate gene polymorphisms as biomarkers in predicting the efficacy of therapy ( $\mathrm{TNF} \alpha$ inhibitors) and in determining the progression (its rate) of structural damage in the spine.

In response to the first question raised on the relationship between the candidate genes and AS, three out of eight genes obtained data on a statistically significant association: CD40 rs4810485, TNFA rs1800629, PTPN22 rs2476601.

When analysing the signaling pathway of the TNF family, CD40 gene was selected as one of the less studied genes associated with AS. This gene has been extensively studied in various autoimmune diseases, including rheumatic diseases. At present, the $C D 40$ rs4810485 $G / T$ polymorphism which affects CD40 expression on the cell surface is one of the polymorphisms extensively analysed in relation to RA and SLE (Lee et al., 2015; Raychaudhuri et al., 2008). To date, no studies have been conducted to establish its association with AS. According to the NCBI dbSNP the major allele and genotype of CD4O rs 4810485 in the population of European origin is $G$ allele and $G G$ genotype which is also observed in the current study control group. 
The study identified the relationship of CD40 rs4810485 with AS: GT, TT genotypes and the minor $T$ allele were associated with an increased risk, while the homozygous $G G$ genotype was a protective form.

The second gene involved in the signaling pathway of the TNF family and according to our study with AS is $\boldsymbol{T N F A}$. The G/A polymorphism of this gene affects the synthesis of TNFa (Bayley et al., 2004). In the analysis of the allele distribution in the AS and control group, it was found that the minor allele in both groups was $A$, corresponding to the data of the population of European origin $(N C B I d b S N P)$.

According to the study data, the minor $A$ allele and $A A$ genotype of the rs1800896 polymorphism are protective forms. Similar data on the protective role of the $A$ allele can be found in a study of the Bulgarian AS patient group (Manolova et al., 2014).

When analysing haplotypes formed by SNPs of both TNF family genes, it was found that haplotype $A G$ formed by TNFA rs 1800629 minor allele $A$ and $C D 40$ rs4810485 major allele $G$ is a disease-protecting haplotype. Thus, the study data showing the involvement of both genes in the development of AS demonstrate the significance of the TNF signaling pathway in the pathogenesis of the disease.

There are results of individual studies of the Chinese AS patients (Ma et al., 2017; Sun et al., 2013) and the data of AS patients of European origin (data from metaanalysis) (Lee, Song, 2009) which do not confirm the association of this polymorphism with AS contrary to the current study. There are also publication data confirming our results on the TNFA rs1800629 relationship with AS, e. g. AS patients studies data coming from Bulgaria (Manolova et al., 2014), Norway (Nossent et al., 2014), Denmark (Sode et al., 2018).

Although the analysed polymorphism may be associated with the disease, this does not exclude differences in the distribution of genotypes. For example, a study of Brazilian AS patients demonstrates that $A A$ and $G A$ genotypes of the 
TNFA rs1800629 are associated with the risk of development of AS and SpA (Rocha Loures et al., 2018), contrary to the results of the current study where the $A A$ genotype has a protective form. In addition, it should be noted that no heterozygous genotype was identified in the study, either in the control or in the AS group. These differences, possibly attributable to the analysis of different origin populations, study criteria, sample number, etc., indicate the relevance of studies on the genetic aspects of different geographical areas of AS.

PTPN22 is the third gene associated with AS, representing the so-called $\mathrm{TNF} \alpha, \mathrm{T}$ lymphocytes and dendritic cell signaling interaction pathway that are essential for maintaining the homeostasis of immune system cells. According to the study, the minor allele of PTPN22 rs2476601 $C / T$ polymorphism was $T$ corresponding to population data of European origin (1000 Genomes Project). The minor $T$ allele was slightly more common in the AS group (32.65\% vs. $22.73 \%$ ) compared to the control group; thus, demonstrating trends for the risk allele but without clinical relevance. In analysis of genotype distribution, no statistically significant difference was found in the current study.

When comparing the frequency of the minor $T$ allele in the European population as a whole and in the control group of the study, it should be noted that the control group has a higher frequency (mean by $13 \%$ ) (MAF (minor allele frequency) in Europe - 0.094 (NCBI dbSNP, 1000 Genomes Project); MAF in the control group -0.227 ). According to the publication, there is a decrease in minor $T$ allele frequencies in Caucasians from northern Europe to southern Europe (Tizaoui et al., 2019). This allele is not present in the African or Asian populations (NCBI dbSNP, 1000 Genomes Project).

This gene has been extensively studied in autoimmune and autoimmunerelated diseases (e. g. RA, SLE, juvenile idiopathic arthritis, etc.) (Tizaoui et al., 2019). The number of publications on the association of the PTPN22 rs2476601polymorphism with AS is very low. A systematic review was published in 2019 which does not confirm its relationship with AS (Tizaoui et 
al., 2019). In contrast, AS patient data from Denmark indicate the protective role of PTPN22 (rs2476601) $1858 \mathrm{C}>\mathrm{T}$ (TT or $C T$ vs. $C C$ ), explaining this with possible reduction of TNF $\alpha$ levels in the blood (Sode et al., 2018).

While collecting data to answer the first question raised, disease-related SNPs of three genes were identified in the study: TNFA $r$ s1800629 with risk allele $G, C D 40$ rs4810485 with risk allele $T$ and $P T P N 22$ rs2476601 with risk allele $T$. Haplotype GTT formed by the risk alleles of these genes increased the probability of development of AS more than 3.5 times. Overall, analysis of the data revealed that three forms of haplotypes were risk forms (GTT, GTC, GGT) and three forms were protective of $\mathrm{AS}(G G C, A G C, A G T)$. The highest protective level was haplotype $A G T$, which reduced the probability of development of AS approximately 4.5 to 5.6 times.

It is important to note that in all three risk forms, TNFA rs1800629 contained a risk allele $G$ and in the case of all three of the disease-protecting haplotypes, the $C D 40$ rs 4810485 locus had a protective allele $G$, thus confirming the role of TNF family proteins in the pathogenesis of AS. So far, no data on the haplotype analysis formed by SNPs of TNFA and CD40 genes in AS have been found in scientific publications.

The second question raised in the study was the association of selected candidate gene SNPs with the most common extraspinal manifestations of AS uveitis and peripheral arthritis. Analysing the association of eight candidate gene polymorphisms with AS uveitis and peripheral arthritis, four genes (IL10, TGFB1, IRF5 and ERAP1) were found to be associated with uveitis and/or peripheral arthritis. It should be noted that none of the polymorphisms of these genes was associated with AS in the study.

The minor $G$ allele of $I L 10$ rs1800896 G/A polymorphism corresponding to the frequency of the MAF in Europe (NCBI dbSNP, 1000 Genomes Project) was protective of uveitis development: in the group with uveitis, this allele was $21 \%$ less frequent compared to the group without uveitis (31.82\% vs. $53.08 \%$ ). 
This relationship was also observed in the genotype distribution: $G G$ genotype was protective against uveitis with the level of clinical significance. The risk of $A A$ genotype for development of uveitis was clinically significant. In contrast, the heterozygous genotype had a similar frequency in AS groups with and without uveitis.

Another finding that confirmed the role of the $G$ allele of $I L 10$ rs 1800896 in AS uveitis was the analysis of four subgroups of AS patients (with uveitis and/or peripheral arthritis). In this analysis, data were obtained that the distribution of alleles across all groups was statistically significantly different with the rarest occurrence of the $G$ allele exactly in the group with uveitis compared to the other patient groups and the control group. This polymorphism has been extensively studied in other diseases, such as RA (de Paz et al., 2010), but the association of IL1O rs1800896 G/A polymorphism with AS uveitis has not yet been described.

During analysis of the haplotypes formed by IL10 rs1800896 ( $G$ allele) and $T G F \beta 1$ rs 1800469 , rs1800470, three haplotypes that protect against uveitis development (GCC, GTC and GCT) were found, whereas the fourth haplotype $G T T$ was the risk form for the development of uveitis and peripheral arthritis as well as the risk form for the development of second manifestation in case of baseline presence of uveitis or peripheral arthritis. Moreover, this haplotype, analysed only in relation to uveitis, was not of high OR value, thus indicating that it was important in the case of both manifestations.

These results point to two aspects: first, the protective role of the ILIO rs180096 $G$ allele against uveitis, and second, the importance of gene interactions, thereby increasing or decreasing the individual risk of the expression of each gene.

The second gene that was found to be associated with AS uveitis was IRF5. In analysing the relationship between the three SNPs (rs10954213, rs2004640, rs3757385) of this gene and uveitis, it was determined only for one 
SNP (rs3757385) at genotype level and only with uveitis. In this case, GT genotype was the risk form with an estimated clinical significance. The homozygous $G G$ genotype, where the major $G$ allele was also the major allele in the population of European descent (NCBI dbSNP, 1000 Genomes Project), was the protective form at the level of clinical significance.

After reviewing the $N C B I d b S N P$ scientific publications about this SNP through the period of middle of 2019, it was concluded that none of them was related to AS or AS uveitis. Thereby, the data obtained in the current study is novelty in the exploration of AS uveitis.

When combining all three SNPs (rs10954213, rs2004640, rs3757385) of IRF5 for the formation of haplotypes, a statistically significant association was found between the distribution of haplotypes and uveitis. The most frequent GTT haplotype which was composed of the rare alleles of SNPs could be considered as the risk haplotype for the development of uveitis. On the other hand, two were considered as protective haplotypes: $G G G$, which occurred only in patients without uveitis $(7.69 \%$ ), and $A G G$, which occurred in $18.18 \%$ of patients with uveitis and $30.00 \%$ of patients without uveitis. In addition, data from other studies (e. g. systemic sclerosis) indicate that the analysis of these haplotypes formed by IRF5 SNPs is more informative compared to the individual SNP analysis (Dieude et al., 2010).

Considering that in the current study the statistically significant relationship with uveitis was found only for two SNPs of two genes: IRF5 rs3757385 with possible (association just on the level of genotypes) risk $T$ allele and ILIO rs 1800896 with the risk $A$ allele, haplotypes formed by these two SNPs were analysed for the possible association with uveitis. Data analysis revealed that TA haplotype formed by the risk alleles from both loci had a high but not clinically significant OR. In contrast, $G G$ haplotype was a protective form with the highest clinical significance. These data indicate that it is important to include 
multiple SNPs of a single gene or multiple SNPs of uveitis-related genes forming haplotypes for the analysis of the risk of AS uveitis.

In analysis of the association of selected AS candidate genes with peripheral arthritis, the relationship was found with two genes: TGF 1 rs 1800469 in the distribution of alleles and ERAPI rs10050860 in the distribution of genotypes.

For the $\boldsymbol{T G F \boldsymbol { \beta } 1}$ rs 1800469 polymorphism, the study found an association with AS peripheral arthritis in allelic distribution. The control group's minor allele was $C$ (MAF 0.442), which is different from the European population, where the minor allele is $T$ (MAF 0.312) (NCBI dbSNP, 1000 Genomes Project). The major $T$ allele was a form of risk for peripheral arthritis development in AS patients. Similar data on the frequency of alleles for the control group have been reported for the East Asian population, where the MAF of $C$ allele is 0.453 (NCBI dbSNP, 1000 Genomes Project).

One of the issues in the analysis of the role of TGF $\beta 1$ in the course of AS is its possible link to the process of ossification which is a part of AS pathogenesis (Eftekhari et al., 2018; Jaakkola et al., 2004). A review of the NCBI dbSNP (27.07.2019), which mentions 173 publications, did not find scientific publications on the TGFB1 rs1800469 polymorphism in the context of AS. Therefore, the current study data on the relationship of this polymorphism with AS peripheral arthritis are novel.

ERAP1 is another gene of which one of the SNP (rs10050860) was found to be associated with AS peripheral arthritis at the level of genotypes. The frequency of allelic distribution of this polymorphism in the study control group is similar to the European population data (NCBI dbSNP, 1000 Genomes Project). In the AS group with peripheral arthritis the homozygous form $(A A)$ of the minor allele was not detected, but it was found in two patients $(4.88 \%)$ without this extraspinal manifestation. Thus, $A A$ genotype was considered to be a protective form, but $G A$ genotype could be marked as the risk form with clinical 
significance. The homozygous form $(G G)$ of the major allele was also identified as a protective genotype. In this case, the alleles of ERAPl rs 10050860 polymorphism show incomplete dominance where both alleles are equally important and their interaction is significant.

The association of the ERAPI rs10050860 heterozygous genotype directly with peripheral arthritis is also supported by the analysis of the distribution of all genotypes of this SNP: heterozygous genotype in the group with peripheral arthritis alone was significantly more frequent than in the other subgroups, and more than five times frequent in comparison with the group without both extraspinal manifestations (39.20\% vs. $7.84 \%)$. In determining the clinical significance of the relationship with the heterozygous form, only the peripheral arthritis and both extraspinal manifestations had the highest clinical relevance.

At the beginning of the discussion on the role of ERAP1 in the context of AS, it should be noted that the detection of this gene is one the largest benefits of GWAS studies, identifying it as a second gene after $H L A-B * 27$ (WTCCC et $a l$., 2007). This is a major step forward in the understanding of the pathogenesis of AS, highlighting the role of aminopeptidases in the course of AS (Kenna, Brown, 2013). The association of its polymorphisms (including rs10050860, rs30187, rs26653) with AS in different populations has been confirmed by subsequent genetic studies, but data are inconsistent (Hanson et al., 2019; Yao et al., 2019).

The Hungarian AS patient study identified the relationship of ERAP1 rs10050860 to AS, but did not detect association with AS peripheral arthritis (Pazar et al., 2009). Other studies available in NCBI dbSNP have not analysed the association of this polymorphism with AS peripheral arthritis.

The publications indicate that the association of ERAPl with AS is primarily contributed by individual common ERAPl genotypes, rather than by haplotypes ( $L i$, Brown, 2017). In the study evaluating the haplotypes of all three 
SNPs, no association with AS or any of the analysed extraspinal manifestations of AS were not identified.

In analysis of the AS group for peripheral arthritis, a statistically significant association was found in two SNPs: TGF 1 rs1800469 with risk $T$ allele and ERAP1 rs10050860 with the risk GA genotype (both homozygous genotypes were protective). When analysing the distribution of haplotypes of two specific loci in AS patients with and without peripheral arthritis, it was found that the differences in frequency between groups were not statistically significant. The possible explanation for that can be the association of ERAPI rs10050860 with peripheral arthritis on the genotype level, not at the allelic level, and the heterozygous form (interaction of both alleles) was a risk form.

When combining SNPs of uveitis and peripheral arthritis-associated loci in a single haplotype, IRF5 rs3757385, ERAP1 rs10050860, IL10 rs1800896 and TGFB1 rs1800469 analysis data were used in association with AS uveitis and/or peripheral arthritis. Analysing the distribution of common haplotypes in four subgroups of AS patients, it was found that the difference in the frequency distribution was not statistically significant. Thus, all four loci were generally unrelated to uveitis and/or peripheral arthritis. These data indicate that not only the polymorphism of the specific SNP of a given gene is essential in the research and analysis of genetic aspects, but also the inclusion of SNPs of different genes, thereby clarifying the relevance of SNP of one gene to any of the analysed features in the context of SNPs of other genes and creating more accurate maps of the genetic risk of the disease.

The number of studies on the polymorphisms of AS candidate genes in relation to AS peripheral arthritis or uveitis is low. Similar to the results of the current study, no association was found analysing AS patient data from Germany on the association of TNFA rs1800629 with peripheral arthritis or uveitis (Poddubnyy et al., 2011). In the Norwegian AS patients' study, the presence of 
the TNFA rs1800629 A allele in the genotype reduced the risk of uveitis (Nossent et al., 2014).

In the study another gene was analysed, which is the second significant non-MHC gene in relation to AS - IL23R. This gene, whose association with AS was detected in 2007, encodes the IL-23 receptor (IL23R), thereby affecting the IL-23/IL-17 signaling pathway (Costantino et al., 2018; WTCCC et al., 2007). Within the framework of the study, the association was analysed of three SNPs of $I L 23 R$ - rs10889677, rs11209026, rs2201841 - with AS. No association was found between these three IL23R polymorphisms and AS, though according to several scientific publications such association has been demonstrated in European origin populations. This discrepancy may be partly explained by the relatively small number of subjects included in the study. Another explanation is related to possible ethnic differences.

The third question raised in the study was the identification of selected biomarkers for predicting the course of AS and TNF $\alpha$ inhibitor therapy.

To answer this question, five aspects of the impact of candidate gene polymorphisms were analysed on: 1) age at onset of first clinical symptoms; 2) assessment of structural damage (mSASSS) analysed in the context of the disease duration; 3) assessment of the efficacy of the first year of treatment with $\mathrm{TNF} \alpha$ inhibitors; 4) disease transition into an inactive form (assessed by BASDAI) during the first year of treatment with TNF $\alpha$ inhibitors; 5) tendencies of changes in the disease activity assessment (BASDAI) during the first treatment year with $\mathrm{TNF} \alpha$ inhibitors.

As a starting point for discussion of these five aspects, it should be noted that the number of studies on these (as key issues to be mentioned in the titles and/or aims of the study) is relatively small in terms of both the genetic aspects of AS disease and in the context of chosen AS candidate genes; therefore, the comparison of our data on SNPs of candidate genes was made by analysing data from study descriptions within the available scientific publications. 
The age at onset of first clinical symptoms of AS is one of the risk factors for the progression of the disease - the earlier the age, the more aggressive the course of the disease (Amort et al., 1994; Pradeep et al., 2008). However, there are publications indicating that early age in itself does not affect the structural damage caused by the disease, as well as the activity of the disease and extraspinal manifestations (Brophy, Calin, 2000).

In the study, by analysing genotype distribution, none of the 15 SNPs had a statistically significant effect on the age at onset of first AS symptoms. This is consistent with the data from the Portuguese AS patient study where the lack of association of IL23R rs10889677, rs11209026 and ERAPI rs30187 polymorphisms was found (Pimentel-Santos et al., 2009). Similar results were obtained from the analysis of the role of TGF $\beta 1$ rs 1800469 polymorphism in Finnish and English families (Jaakkola et al., 2004) and TNFA rs1800629 polymorphism in Norwegian (Nossent et al., 2014) and German studies with AS patients (Poddubnyy et al., 2011).

In contrast, in the analysis of French AS patient data, the protective $A$ allele of the $I L 23 R$ rs 11209026 polymorphism was less common in patients with early onset of symptoms (Kadi et al., 2013). Analysis of AS patient data from Bulgarian study revealed the effect of $A$ allele of the TNFA rs1800629 in preventing early onset of the disease (Manolova et al., 2014). Scientific publications do not describe the study data that would include the information about the analysis of the possible association between the SNPs of the chosen AS candidate genes and the age at onset of first clinical symptoms.

Evaluation of the course of the disease based on the progression of the structural damage was done using the radiographic changes in cervical and lumbar spine (mSASSS) and its relation to the duration of the disease. As a result of the analysis, data were obtained only for one SNP of the candidate gene IRF5 rs10954213 for the relationship with structural changes depending on duration of the disease. 
The minor $G$ allele of the IRF5 rs 10954213 in both $G G$ and $G A$ genotypes was a risk form for a more pronounced increase in mSASSS with each year of the disease (in the presence of $G G$, each subsequent year of the disease increased mSASSS by 1.72 points in $40.49 \%$ of cases; in the presence of $A G$ genotype by 1.37 points) compared to the effect of the major $G$ allele.

Contrary to the findings of RA studies, the major $A$ allele is a form of risk (Liu et al., 2013). Of course, it has to be taken into account that RA is a pathogenetically and therefore clinically different disease compared to AS. However, it is possible that this difference in results again raises the question of the association of inflammation and structural damage (erosive damage with osteoproliferation) in the pathogenesis of AS - are these processes two consecutive components of the same process or are they two different processes? In assessing the potential relationship of the polymorphisms of these candidate genes with structural damage in the context of AS or SpA, it is necessary to note the results of Kadi and co-authors in the analysis of French SpA patients, including the association with $I L 23 R$ rs 11209026 (Kadi et al., 2013). In view of the association of $A$ allele of this SNP with the risk reducing effect to structural damage and early age for AS, the study authors of the French SpA patient group point out that this polymorphism may have a greater impact on the severity of the disease course than on the risk of its development.

The study data are consistent with the analysis of the genetic aspects of the Portuguese AS patients where the relationship between IL23R rs10889677, rs11209026, ERAP1 rs30187 polymorphisms and mSASSS was not established (Pimentel-Santos et al., 2009). Similar data on the lack of association between TNFA rs1800629 and mSASSS were obtained by analysing data of the AS patients study from Germany (Poddubnyy et al., 2011).

When analysing the relationship of genetic aspects with the effects of treatment with TNF $\alpha$ inhibitors, none of the polymorphisms of the candidate genes, including the genes for which we identified a relationship with the risk of 
development of AS, had any impact on the efficacy of the treatment defined in the study.

The number of pharmacogenomic studies on genes involved in the pathogenesis of AS to analyse the differences of polymorphisms in individuals with divergent response to the treatment with $\mathrm{TNF} \alpha$ inhibitors is negligible. A recently published study of AS patients, similar to the current study data, did not identify an association of $I L 10 \mathrm{rs} 1800896 \mathrm{~A} / G$ polymorphism with TNF $\alpha$ inhibitors treatment response prediction (Polo Y La Borda et al., 2019). This is in contrast to another AS study, where a risk allele $A$ has been identified for ineffective TNF $\alpha$ inhibitor treatment (Schiotis et al., 2013).

In the study, the effect of TNFA rs1800629 G/A polymorphism was not determined on the first year efficacy of $\mathrm{TNF} \alpha$ inhibitor therapy, although some scientific reports did (Nossent et al., 2014; Whirl-Carillo et al., 2012). There are publications consistent with the current study data on the lack of relationship ( $M a$ et al., 2017; Manolova et al., 2014).

The association of gene polymorphisms with treatment efficacy, which in our view consists of evaluation of three sub-questions (inactive disease or remission, improvement and trends in the changes of disease activity), is usually not explored in the studies by distinguishing these points. In the clinician's assessment, there is a significant difference between the defined therapeutic effect, which provides a definite improvement (BASDAI difference evaluated between baseline data and follow-up assessment), and an inactive disease, so in the study all three sub-questions were analysed.

TNFA rs1800629 G/A polymorphism is one of three AS candidate genes that were found to be associated with the transition of the disease to inactive form during the first year of treatment with $\mathrm{TNF} \alpha$ inhibitors at allelic level. In the TNF $\alpha$ inhibitor treatment group, the rare $A$ allele was not detected in any patient with active disease, only in patients with inactive disease. These results indirectly 
demonstrate the potential role of TNFA rs1800629 in determining the efficacy of treatment.

The other two genes that were identified in relation to the transition of disease into inactive form during the first year of treatment with TNF $\alpha$ inhibitors were ERAPI (rs10050860) and ILIO (rs1800896).

In the case of ERAP1 rs 10050860 , the association was determined only by the genotype distribution: $G G$ genotype contributed to the transition of the disease in inactive form in the first year following initiation of treatment with $\mathrm{TNF} \alpha$ inhibitors. In addition, the heterozygous form was an encouraging form for the maintenance of disease activity.

For IL10 rs 1800896 polymorphism, the association was found only in the distribution of genotypes. The heterozygous genotype $G A$ with clinical relevance facilitated the maintenance of the disease in an active form during the treatment. It should be noted that of the more than 300 publications cited in the NCBI dbSNP database (17.07.2019) on IL10 rs1800896 polymorphism, there is only one publication on AS, which provides data on this SNP (risk $A$ allele) as one of the prognostic indicators of $\mathrm{TNF} \alpha$ inhibitor treatment non-response, estimated to be less than $50 \%$ improvement in BASDAI from baseline (Schiotis et al., 2013).

In the first year of treatment with TNF $\alpha$ inhibitors, only the SNP of one gene - IRF5 rs3757385 - have been identified to play a role in analysing the trends in the assessment of disease activity. In this case, the presence of a minor $T$ allele in the genotype increased the change in BASDAI during the first year of treatment with TNF $\alpha$ inhibitors, contributing to a reduction in its value. Thus, the determined genotype allows predicting the magnitude of the potential reduction in BASDAI by comparing baseline data before initiating TNF $\alpha$ inhibitors and after the first year of therapy. It provides insight into the phenotypic manifestation of the disease in a particular individual, thereby predicting the course of the disease. 
The creation of a genetic map for any disease is a very gradual and complex process that depends on many factors, including the ethnicity and geographical location of the study population. Establishing a genetic risk scale for AS may contribute to early diagnosis and reduce late detection, which is still an average of eight to ten years worldwide. The course of AS is very diverse, so predicting it would help to choose the optimal strategy for therapy. To realise this goal, candidate gene studies of several possible pathogenetic pathways are needed, analysing the data according to clinical picture aspects.

The limitations of the present study were related to the relatively small number of AS patients, as well as the lack of assessment of structural damage in the dynamic to determine the more accurate effect of candidate gene polymorphisms. Although the data from our study on patient distribution in relation to the frequency of uveitis and peripheral arthritis in AS are consistent with the data from scientific publications, it should be noted that uveitis and peripheral arthritis are manifestations of AS that may occur during lifetime, thereby reducing the number of patients in the group of patients who did not have these changes during the period covered by this study. 


\section{Conclusions}

1. The database of patients with ankylosing spondylitis (AS) is established according to the original questionnaire, the analysis of which describes the profile of AS patients as well as the clinical expression groups.

- The average AS patient is a 39-year-old male with the onset of the first symptoms of the disease at the average age of 26 , with active disease, restrictions of spinal mobility, impaired daily activity and moderate self-assessment of fatigue and back pain and radiographically visualised structural damage of cervical and lumbar spine which correlates with the evaluation of functional ability and spinal mobility.

- In the AS patient group, 58.16\% have peripheral arthritis and $33.67 \%$ have uveitis. Patients with uveitis have a longer disease course than patients without uveitis. In the case of peripheral arthritis, patients have a higher disease activity. Patients with peripheral arthritis and uveitis have the highest rates of disease activity, self-assessment of joint pain and longer disease duration.

2. Candidate gene polymorphisms $C D 40$ rs4810485 with protective allele $G$ and genotype $G G, T N F A$ rs1800629 with protective allele $A$ and genotype $A A$ and PTPN22 rs2476601 with protective allele $C$ are all related to AS.

3. The haplotypes of the combinations of the candidate gene TNFA rs 1800896 G/A, CD40 rs4810485 G/T and PTPN22 rs2476601 C/T polymorphisms are related to AS.

- The highest protective level was detected for the haplotype AGT.

- The highest risk level was detected for the haplotype GTT.

4. The polymorphisms of four candidate genes are related to AS extraspinal manifestations - uveitis and/or peripheral arthritis. 
- In case of uveitis: IL10 rs1800896 with the risk allele $A$ and genotype $A A, I R F 5$ rs3757385 with the risk genotype GT.

- In case of peripheral arthritis: TGF 1 rs1800469 with the risk allele $T$ and $E R A P 1$ rs10050860 with the risk genotype $G A$.

- In the case of uveitis and peripheral arthritis: ERAP1 rs10050860 with the risk genotype $G A$ and $I L 10$ rs1800896 with the risk allele $A$.

5. Haplotypes of multiple candidate gene polymorphism combinations are associated with AS uveitis and/or peripheral arthritis.

In the case of uveitis the relationship is with:

- the combination of IRF5 rs10954213, rs2004640 and rs3757385 polymorphisms with the risk haplotype GTT;

- the combination of IL10 rs1800896, TGFß1 rs1800469 and 1800470 polymorphisms with the risk haplotypes $G T T$ and $A C T$;

- the combination of IRF5 rs3757385 and IL1O rs1800896 polymorphisms with the risk haplotypes $T A$ and $G A$.

In the case of peripheral arthritis the relationship is with:

- the combination of IL10 rs1800896, TGF 1 rs1800469 and 1800470 polymorphisms with the risk haplotype GTT and the protective haplotype $A C T$ in the case of uveitis.

6. Multiple candidate gene polymorphisms are linked to the selected AS biomarkers (progression of structural damage measured by mSASSS depending on the disease duration and change in disease activity during the first year of treatment with TNF $\alpha$ inhibitors).

- The minor allele $G$ of IRF5 rs 10954213 in the homozygous as well as heterozygous genotype is associated with the progression of AS spinal structural damage depending on the disease duration.

- The allele $A$ of TNFA rs1800629, the genotype GG of ERAP1 rs10050860 and the genotype GA of ILIO rs1800896 are linked to the 
disease transition to the inactive form during the first year of treatment with TNFa inhibitors.

- The presence of the minor allele $T$ of IRF5 rs3757385 increases the BASDAI changes during the first year of treatment with TNF $\alpha$ inhibitors, thus reducing BASDAI value.

7. Genotypes of candidate gene polymorphisms are not associated with the age at the onset of first AS symptoms.

The hypothesis of the study is confirmed: of the 15 candidate gene polymorphisms analysed, seven polymorphisms are linked to AS and/or its clinical manifestations (uveitis and/or peripheral arthritis), and/or treatment efficacy with TNF $\alpha$ inhibitors. 


\section{Recommendations}

In the light of the results of the study, it is currently not possible to provide practical recommendations for clinical trials with patients, as further studies are required (see below) to test the polymorphisms of the candidate genes (i.e. the association of the polymorphisms of the candidate genes with the disease, its manifestations, biomarkers of the disease) as molecular markers for the usage in clinical practice.

These recommendations are intended for further research by a team of molecular biologists, genetics and rheumatologists.

1. The studies at cellular and candidate gene-coded protein level should be performed in order to determine the significance of the polymorphisms of the candidate genes (ERAP1 rs10050860 G/A, CD40 rs4810485 G/T, IL10 rs1800896 A/G, TGFB1 rs1800469 C/T, rs1800470 T/C, IRF5 rs10954213 $A / G, \operatorname{rs} 2004640 T / G, \operatorname{rs} 3757385 G / T, P T P N 22 \operatorname{rs} 2476601 C / T)$ in the development of AS and its clinical manifestations (uveitis and peripheral arthritis).

2. The clinical studies should be performed with patients with inflammatory back pain without radiographically seen spinal structural changes, i.e. non-radiographic axial SpA, and with patients with approved AS diagnosis in order to determine the significance of the specific SNP of the candidate gene as molecular marker in relation to AS and its clinical manifestations:

- patients with inflammatory back pain without radiographically visualised spinal structural changes (non-radiographic axial $\mathrm{SpA}$ ) should be tested for CD40 rs4810485 G/T, TNFA rs1800629 G/A and PTPN22 rs2476601 $C / T$ polymorphisms in order to assess the risk of the AS development; 
- patients with approved AS diagnosis should be tested for IRF5 rs3757385 G/T, IL10 rs1800896 A/G, TGFB1 rs1800469 C/T, ERAPI rs10050860 G/A polymorphisms in order to assess the risk for the development of AS uveitis and/or peripheral arthritis;

- patients with approved AS diagnosis should be tested for IRF5 rs10954213 $A / G$ polymorphism in order to assess the risk of aggressive disease course (i.e. the assessment of the risk of severe spinal structural damage);

- patients with approved AS diagnosis should be tested for ERAP1 rs10050860 G/A, TNFA rs1800629 G/A, IL10 rs1800896 A/G and IRF5 rs3757385 $G / T$ polymorphisms in order to assess the efficacy of treatment with TNF $\alpha$ inhibitors. 


\section{References}

1. Amor, B., Santos, R. S., Nahal, R., et al. 1994. Predictive factors for the longterm outcome of spondyloarthropathies. J Rheumatol. 21(10), 1883-1887.

2. Baraliakos, X., Haibel, H., Listing, J., et al. 2014. Continuous long-term anti-TNF therapy does not lead to an increase in the rate of new bone formation over 8 years in patients with ankylosing spondylitis. Ann Rheum Dis. 73(4), 710-715.

3. Bayley, J. P., Ottenhoff, T. H. M., Verweij, C. L. 2004. Is there a future for TNF promoter polymorphisms? Genes Immun. 5(5), 315-329.

4. Braun, J., Baraliakos, X., Deodhar, A., et al. 2017. Effect of secukinumab on clinical and radiographic outcomes in ankylosing spondylitis: 2-year results from the randomised phase III MEASURE 1 study. Ann Rheum Dis. 76, 1070-1077.

5. Braun, J., Kiltz, U., Heldmann, F., et al. 2015. Emerging drugs for the treatment of axial and peripheral spondyloarthritis. Expert Opin Emerg Drugs. 20(1), 1-14.

6. Braun, J., Baraliakos, X., Hermann, K. G. A., et al. 2016. Serum C-reactive Protein Levels Demonstrate Predictive Value for Radiographic and Magnetic Resonance Imaging Outcomes in Patients with Active Ankylosing Spondylitis Treated with Golimumab. J Rheumatol. 43(9), 1704-1712.

7. Brophy, S., Calin, A. 2001. Ankylosing spondylitis: interaction between genes, joints, age at onset, and disease expression. J Rheumatol. 28(10), 2283-2388.

8. Brown, M. A. 2008. Breakthroughs in genetic studies of ankylosing spondylitis. Rheumatology (Oxford). 47(2), 132-137.

9. Brown, M. A., Kenna, T. J., Wordsworth, B. P. 2016. Genetics of ankylosing spondylitis-insights into pathogenesis. Nat Rev Rheumatol. 12, 81-91.

10. Brown, M. A., Laval, S. H., Brophy, S., et al. 2000. Recurrence risk modelling of the genetic susceptibility to ankylosing spondylitis. Ann Rheum Dis. 59 (11), 883-886.

11. Brown, M. A., Wordsworth, B. P. 2018. Genetics in ankylosing spondylitis Current state of the art and translation into clinical outcomes. Best Pract Res Clin Rheumatol. 31(6), 763-776.

12. Bujang, M. A., Baharum, N. 2017a. Guidelines of the minimum sample size requirements for Cohen's Kappa. Epidemiol Biostat Public Health. 14(2), e12267.

13. Bujang, M. A., Baharum, N. 2017b. A simplified guide to determination of sample size requirements for estimating the value of intraclass correlation coefficient: a review. Arch Orofac Sci. 12(1), 1-11.

14. Calin, A., Garrett, S., Whitelock, H., et al. 1994. A new approach to defining functional ability in ankylosing spondylitis: the development of the Bath Ankylosing Spondylitis Functional Index. J Rheumatol. 21(12), 2281-2285.

15. Chu, C. J., Barker, S. E., Dick, A. D., et al. 2012. Gene Therapy for Noninfectious Uveitis. Ocul Immunol Inflamm. 20(6), 394-405.

16. Costantino, F., Breban, M., Garchon, H. J. 2018. Genetics and Functional Genomics of Spondyloarthritis. Front Immunol. 9, 2933. Available at: doi:10.3389/fimmu.2018.02933 [viewed 07.03.2019.].

17. Creemers, M. C., Franssen, M. J., van't Hof, M. A., et al. 2005. Assessment of outcome in ankylosing spondylitis: an extended radiographic scoring system. Ann Rheum Dis. 64, 127-129. 
18. Criswell, L. A., Pfeiffer, K. A., Lum, R. F., et al. 2005. Analysis of families in the multiple autoimmune disease genetics consortium (MADGC) collection: the PTPN22 620W allele associates with multiple autoimmune phenotypes. Am J Hum Genet. 76(4), 561-571.

19. Croft, M., Siegel, R. M. 2017. Beyond TNF: TNF superfamily cytokines as targets for the treatment of rheumatic diseases. Nat Rev Rheumatol. 13(4), 217-233.

20. Davis. J. C., Dougados, M., Braun, J., et al. 2006. Definition of disease duration in ankylosing spondylitis: reassessing the concept. Ann Rheum Dis. 65(11), 1518-1520.

21. de Paz, B., Alperi-Lopez, M., Ballina-Garcia, F. J., et al. 2010. Interleukin 10 and Tumor Necrosis Factor- $\alpha$ Genotypes in Rheumatoid Arthritis - Association with Clinical Response to Glucocorticoids. J Rheum. 37(3), 503-511.

22. de Winter, J. J., van Mens, L. J., van der Heijde, D., et al. 2016. Prevalence of peripheral and extra-articular disease in ankylosing spondylitis versus nonradiographic axial spondyloarthritis: a meta-analysis. Arthritis Res. Ther. 18, 196. Available at: doi:10.1186/s13075-016-1093-z [viewed 18.10.2018.].

23. Dieude, P., Dawidowicz, K., Guedj, M., et al. 2010. Phenotype-Haplotype Correlation of IRF5 in Systemic Sclerosis: Role of 2 Haplotypes in Disease Severity. J Rheumatol. 37(5), 987-992.

24. Eftekhari, H., Hosseini, S. R., Pourreza Baboli, H., et al. 2018. Association of interleukin-6 (rs1800796) but not transforming growth factor beta 1 (rs1800469) with serum calcium levels in osteoporotic patients. Gene. 671, 21-27.

25. el Maghraoui, A. 2011. Extra-articular manifestations of ankylosing spondylitis: prevalence, characteristics and therapeutic implications. Eur J Intern Med. 22(6), 554-560.

26. Elewaut, D, Matucci-Cerinic, M. 2009. Treatment of ankylosing spondylitis and extra-articular manifestations in everyday rheumatology practice. Rheumatology (Oxford). 48(9), 1029-1035.

27. Feldtkeller, E., Bruckel, J., Khan, M. A. 2000. Scientific contributions of ankylosing spondylitis patient advocacy groups. Curr Opin Rheumatol. 12(4), 239-247.

28. Fife, M. S., Gutierrez, A., Ogilvie, E. M., et al. 2006. Novel IL10 gene family associations with systemic juvenile idiopathic arthritis. Arthritis Res Ther. 8(5), R148. Available at: doi:10.1186/ar2041 [viewed 23.07.2019.].

29. Garrett, S., Jenkinson, T., Kennedy, L. G., et al. 1994. A new approach to defining disease status in ankylosing spondylitis: the Bath Ankylosing Spondylitis Disease Activity Index. J Rheumatol. 21, 2286-2291.

30. Gathungu, G., Zhang, C. K., Zhang,. W, et al. 2012. A two-marker haplotype in the IRF5 gene is associated with inflammatory bowel disease in a North American cohort. Genes Immun. 13(4), 351-355.

31. Goedecke, V., Crane, A. M., Jaakkola, E., et al. 2003. Interleukin 10 polymorphisms in ankylosing spondylitis. Genes Immun. 4(1), 74-76.

32. Hammer, Ø., Harper, D. A. T, Ryan, P. D. 2001. PAST: Paleontological Statistics Software Package for Education and Data Analysis. Palaeontologia Electronica. 4(1), 9.

33. Hanson, A. L., Morton, C. J., Parker, M. W., et al. 2018. The genetics, structure and function of the M1 aminopeptidase oxytocinase subfamily and their therapeutic potential in immune-mediated disease. Hum Immunol. 80(5), 281-289. 
34. Jaakkola, E., Crane, M. K., Laiho, K., et al. 2004. The effect of transforming growth factor $\beta 1$ gene polymorphisms in ankylosing spondylitis. Rheumatology. 43(1), 32-38.

35. Jenkinson, T. R., Mallorie, P. A., Whitelock, H. C., et al. 1994. Defining spinal mobility in ankylosing spondylitis (AS). The Bath AS Metrology Index. J Rheumatol. 21, 1694-1698.

36. Kadi, A., Costantino, F., Izac, B., et al. 2013. Brief Report: The IL23R Nonsynonymous Polymorphism rs11209026 Is Associated With Radiographic Sacroiliitis in Spondyloarthritis. Arthritis Rheum. 65, 2655-2660.

37. Kenna, T. J., Brown, M. A. 2013. Immunopathogenesis of ankylosing spondylitis. Int J Clin Rheumatol. 8(2), 265-274.

38. Kim, T. J., Lee, S., Joo, K. B., et al. 2014. The presence of peripheral arthritis delays spinal radiographic progression in ankylosing spondylitis: Observation Study of the Korean Spondyloarthropathy Registry. Rheumatology (Oxford). 53(8), 1404-1408.

39. Kook, H., Jin, S. H., Lee, S., et al. 2020. Radiographic progression in patients with ankylosing spondylitis according to uveitis based on the observation study of Korean spondyloarthropathy registry. Arch Rheumatol. 35(x), i-vi. Available at: doi:10.5606/ArchRheumatol.2020.7095 [viewed 21.05.2019.].

40. Lee, Y. H., Bae, S. C., Choi, S. J., et al. 2015. Associations between the functional CD40 rs4810485 G/T polymorphism and susceptibility to rheumatoid arthritis and systemic lupus erythematosus: a meta-analysis. Lupus. 24(11), 1177-1183.

41. Lee, Y. H., Song, G. G. 2009. Lack of association of TNF-alpha promoter polymorphisms with ankylosing spondylitis: a meta-analysis. Rheumatology (Oxford). 48(11), 1359-1362.

42. Li, Z., Brown, M. A. 2017. Progress of genome-wide association studies of ankylosing spondylitis. Clin Transl Immunology. 6(12), e163. Available at: doi:10.1038/cti.2017.49 [viewed 17.04.2019.].

43. Liu, H., An, X., Yang, Y., et al. 2013. Association of rs10954213 polymorphisms and haplotype diversity in interferon regulatory factor 5 with systemic lupus erythematosus: A meta-analysis. J Huazhong Univ Sci Technolog Med Sci. 33(1), $15-21$.

44. López-Medina, C., Garrido-Castro, J. L., Castro-Jiménez, J., et al. 2018. Evaluation of quality of life in patients with axial spondyloarthritis and its association with disease activity, functionality, mobility, and structural damage. Clin Rheumatol. 37(6), 1581-1588.

45. Lukas, C., Landewe,' R., Sieper, J., et al. 2009. Development of an ASAS-endorsed disease activity score (ASDAS) in patients with ankylosing spondylitis. Ann Rheum Dis. 68, 18-24.

46. Ma, H. J., Yin, Q. F., Wu, Y., et al. 2017. TNF- $\alpha-308$ polymorphism determines clinical manifestations and therapeutic response of ankylosing spondylitis in Han Chinese. Med Clin (Barc). 149(12), 517-522.

47. Machado, P. M., Landewé, R., van der Heijde, D. 2018. Assessment of SpondyloArthritis international Society (ASAS) Ankylosing Spondylitis Disease Activity Score (ASDAS): 2018 update of the nomenclature for disease activity states. Ann Rheum Dis. 77, 1539-1540. 
48. Malinowski, K. P., Kawalec, P. 2015. The indirect costs of ankylosing spondylitis: a systematic review and meta-analysis. Expert Rev Pharmacoecon Outcomes Res. 15(2), 285-300.

49. Manolova, I., Ivanova, M., Stoilov, R., et al. 2014. Association of single nucleotide polymorphism at position -308 of the tumor necrosis factor-alpha gene with ankylosing spondylitis and rheumatoid arthritis. Biotechnol Biotechnol Equip. 28(6), 1108-1114.

50. Márquez, A., Cénit, M. C., Cordero-Coma, M., et al. 2013. Two functional variants of IRF5 influence the development of macular edema in patients with non-anterior uveitis. PLoS One. 8(10), e76777. Available at: doi:10.1371/journal.pone.0076777 [viewed 23.07.2019].

51. Martelossi Cebinelli, G. C., Paiva Trugilo, K., Badaró Garcia, S., et al. 2016. TGF-1 functional polymorphisms: a review. Eur Cytokine Netw. 27(4), 81-89.

52. McHugh, M. L. 2012. Interrater reliability: the kappa statistic. Biochem Med (Zagreb). 22(3), 276-282.

53. Mease, P. J., Heijde, D., V,. Karki C., et al. 2018. Characterization of Patients With Ankylosing Spondylitis and Nonradiographic Axial Spondyloarthritis in the USBased Corrona Registry. Arthritis Care Res (Hoboken). 70(11), 1661-1670.

54. Molnar, C., Scherer, A., Baraliakos, X., et al. 2018. TNF blockers inhibit spinal radiographic progression in ankylosing spondylitis by reducing disease activity: results from the Swiss Clinical Quality Management cohort. Ann Rheum Dis. 77, 63-69.

55. Nelson, M. R., Tipney, H., Painter, J. L., et al. 2015. The support of human genetic evidence for approved drug indications. Nat Genet. 47(8), 856-860.

56. Nossent, J. C., Sagen-Johnsen, S., Bakland, G. 2014. Tumor Necrosis FactorPromoter -308/238 Polymorphism Association with Less Severe Disease in Ankylosing Spondylitis is Unrelated to Serum TNF- and Does Not Predict TNF Inhibitor Response. J Rheumatol. 41(8), 1675-1682.

57. Pazar, B., Safrany, E., Gergely, P., et al. 2009. Association of ARTS1 Gene Polymorphisms with Ankylosing Spondylitis in the Hungarian Population: The rs27044 Variant Is Associated with HLA-B*2705 Subtype in Hungarian Patients with Ankylosing Spondylitis. J Rheumatol. 37(2), 379-384.

58. Peters, A. L., Stunz, L. L., Bishop, G. A. 2009. CD40 and Autoimmunity: The Dark Side of a Great Activator. Semin. Immunol. 21(5), 293-300.

59. Pimentel-Santos, F. M., Ligeiro, D., Matos, M., et al. 2009. Association of IL23R and ERAP1 genes with ankylosing spondylitis in a Portuguese population. Clin Exp Rheumatol. 27(5), 800-806.

60. Poddubnyy, D. A., Marker-Hermann, E., Kaluza-Schilling, W., et al. 2011. Relation of HLA-B27, Tumor Necrosis Factor- Promoter Gene Polymorphisms, and T Cell Cytokine Production in Ankylosing Spondylitis -- A Comprehensive GenotypePhenotype Analysis from an Observational Cohort. J Rheumatol. 38(11), 2436-2441.

61. Polo Y La Borda, J., Campos, J., Sanz, J., et al. 2019. Predictive clinical-genetic model of long-term non-response to tumor necrosis factor-alpha inhibitor therapy in spondyloarthritis. Int J Rheum Dis. 22(8), 1529-1537.

62. Pradeep, D. J., Keat, A., Gaffney, K. 2008. Predicting outcome in ankylosing spondylitis. Rheumatology (Oxford). 47(7), 942-945. 
63. Proft, F., Poddubnyy, D. 2018. Ankylosing spondylitis and axial spondyloarthritis: recent insights and impact of new classification criteria. Ther Adv Musculoskelet Dis. 10(5-6), 129-139.

64. Raffeiner, B., Ometto, F., Bernardi, L., et al. 2014. Inefficacy or paradoxical effect? Uveitis in ankylosing spondylitis treated with etanercept. Case Rep Med. 2014, 471319. Available at: doi:10.1155/2014/471319 [viewed 08.03.2019.].

65. Raychaudhuri, S., Remmers, E. F., Lee, A. T., et al. 2008. Common variants at CD40 and other loci confer risk of rheumatoid arthritis. Nat Genet. 40(10), 1216-1223.

66. Robinson, P. C., Wordsworth, B. P., Reveille, J. D., et al. 2013. Axial spondyloarthritis: a new disease entity, not necessarily early ankylosing spondylitis. Ann Rheum Dis. 72, 162-164.

67. Rocha Loures, M. A., Macedo, L. C., Reis, D. M., et al. 2018. Influence of TNF and IL17 Gene Polymorphisms on the Spondyloarthritis Immunopathogenesis, Regardless of HLA-B27, in a Brazilian Population. Mediators Inflamm. 2018: 1395823. Available at: doi:10.1155/2018/1395823 [viewed 09.03.2019.].

68. Rovite, V., Wolff-Sagi, Y., Zaharenko, L., et al. 2018. Genome Database of the Latvian Population (LGDB): Design, Goals, and Primary Results. J Epidemiol. 28(8), $353-360$.

69. Rozas, J., Ferrer-Mata, A., Sánchez-DelBarrio, J. C., et al. 2017. DnaSP 6: DNA Sequence Polymorphism Analysis of Large Data Sets. Mol Biol Evol. 34(12), 3299-3302.

70. Rudwaleit, M., Haibel, H., Baraliakos, X., et al. 2009. The Early Disease Stage in Axial Spondyloarthritis: results from the German Spondyloarthritis Inception Cohort. Arthritis Rheum. 60, 717-727.

71. Rudwaleit, M., van der Heijde, D., Landewé, R., et al. 2009. The development of Assessment of SpondyloArthritis international Society classification criteria for axial spondyloarthritis (part II): validation and final selection. Ann Rheum Dis. 68, $777-783$.

72. Ruyssen-Witrand, A., Luxembourger, C., Cantagrel, A., et al. 2019. Association between IL23R and ERAP1 polymorphisms and sacroiliac or spinal MRI inflammation in spondyloarthritis: DESIR cohort data. Arthritis Res Ther. 21(1), 22. Avalaible at:. doi:10.1186/s13075-018-1807-5 [viewed 06.07.2019.].

73. Rusman, T., van Vollenhoven, R. F., van der Horst-Bruinsma, I. E. 2018. Gender Differences in Axial Spondyloarthritis: Women Are Not So Lucky. Curr Rheumatol Rep. 20(6), 35. Available at: doi:10.1007/s1 1926-018-0744-2 [viewed 06.03.2019.].

74. Schiotis, R., Sánchez, A., Escudero, A., et al. 2013. Candidate's single-nucleotide polymorphism predictors of treatment nonresponse to the first anti-TNF inhibitor in ankylosing spondylitis. Rheumatol Int. 34(6), 793-801.

75. Schneeberger, E. E., Marengo, M. F., Dal Pra, F., et al. 2014. Fatigue assessment and its impact in the quality of life of patients with ankylosing spondylitis. Clin Rheumatol. 34(3), 497-501.

76. Sieper, J., Rudwaleit, M., Khan, M. A., et al. 2006. Concepts and epidemiology of spondyloarthritis. Best Prac. Res Clin Rheumatol. 20(3), 401-417.

77. Sode, J., Bank, S., Vogel, U., et al. 2018. Genetically determined high activities of the TNF-alpha, IL23/IL17, and NFkB pathways were associated with increased risk of 
ankylosing spondylitis. BMC Med Genet. 19(1), 165. Available at: doi.org/10.1186/s12881-018-0680-z [viewed 02.03.2019.].

78. Sun, R., Huang, Y., Zhang, H., et al. 2013. MMP-2, TNF- $\alpha$ and NLRP1 polymorphisms in Chinese patients with ankylosing spondylitis and rheumatoid arthritis. Mol Biol Rep. 40(11), 6303-6308.

79. Taurog, J. D., Chhabra, A., Colbert, R. A. 2016. Ankylosing Spondylitis and Axial Spondyloarthritis. N Engl J Med. 374, 2563-2574.

80. Temel, G., Erdogan, S. 2017. Determining the sample size in agreement studies. Marmara Med J. 20, 101-112.

81. Thomas, G. T., Willner, D., Robinson, P. C., et al. 2017. Genetic diagnostic profiling in axial spondyloarthritis: a real world study. Clin Exp Rheumatol. 35(2), 229-233.

82. Tizaoui, K., Kim, S. H., Jeong, G. H., et al. 2019. Association of PTPN22 1858C/T Polymorphism with Autoimmune Diseases: A Systematic Review and Bayesian Approach. J Clin Med. 8(3), 347. Available at: doi:10.3390/jcm8030347 [viewed 02.07.2019.].

83. Uthoff, S. M. S., Hunt, L. E., Grant, B. S., et al. 2002. T-Cell Receptor $\gamma$ : A Microsatellite Marker for Colorectal Cancer. Ann Surg Oncol. 9(1), 88-93.

84. van der Heijde, D., Ramiro, S., Landewé, R., et al. 2017. 2016 update of the ASASEULAR management recommendations for axial spondyloarthritis. Ann Rheum Dis. 76(6), 978-991.

85. van der Linden, S. M., Valkenburg, H. A., Cats, A. 1984. Evaluation of diagnostic criteria for ankylosing spondylitis. A proposal for modification of the New York criteria. Arthritis Rheum. 27, 361-368.

86. Varkas, G., Vastesaeger, N., Cypers, H., et al. 2018. Association of Inflammatory Bowel Disease and Acute Anterior Uveitis, but Not Psoriasis, With Disease Duration in Patients With Axial Spondyloarthritis: Results From Two Belgian Nationwide Axial Spondyloarthritis Cohorts. Arthritis Rheumatol. 70(10), 1588-1596.

87. Wanders, A. J., Landewe, R. B., Spoorenberg, A., et al. 2004. What is the most appropriate radiologic scoring method for ankylosing spondylitis? A comparison of the available methods based on the Outcome Measures in Rheumatology Clinical Trials filter. Arthritis Rheum. 50, 2622-2632.

88. Wellcome Trust Case Control Consortium (WTCCC), Australo-Anglo-American Spondylitis Consortium (TASC), Burton, P. R., et al. 2007. Association scan of 14,500 nonsynonymous SNPs in four diseases identifies autoimmunity variants. Nat Genet. 39(11), 1329-1337.

89. Whirl-Carrillo, M., McDonagh, E. M., Hebert, J. M., et al. 2012. Pharmacogenomics knowledge for personalized medicine. Clin Pharmacol Ther. 92(4), 414-417.

90. Xia, Y., Liang, Y., Guo, S., et al. 2018. Association between cytokine gene polymorphisms and ankylosing spondylitis susceptibility: a systematic review and meta-analysis. Postgrad Med J. 94(1115), 508-516.

91. Yao, Y., Liu, N., Zhou, Z., et al. 2019. Influence of ERAP1 and ERAP2 gene polymorphisms on disease susceptibility in different populations. Hum Immunol. 80(5), 325-334.

92. Zeboulon, N., Dougados, M., Gossec, L. 2008. Prevalence and characteristics of uveitis in the spondyloarthropathies: a systematic literature review. Ann Rheum Dis. 67(7), 955-959. 
93. Zhang, L., Yan, J., Wang, Y. X., et al. 2013. Association of TGF- $\beta 1+869$ C/T promoter polymorphism with susceptibility to autoimmune diseases: a meta-analysis. Mol Biol Rep. 40(8), 4811-4817.

94. Zochling, J., Braun, J. 2005. Assessment of ankylosing spondylitis. Clin Exp Rheumatol. 23(Suppl. 39), S133-S141. 


\section{List of published articles and abstracts and participation in congresses and conferences}

Articles in international scientific journals

1. Zepa, J., Bulina, I., Lavrentjevs, V., Vinkalna, I., Nikitina-Zake, L., Andersone, D., Lejnieks, A. 2018. The Impact of Body Mass Index on Disease Progression in Ankylosing Spondylitis, Proceedings of the Latvian Academy of Sciences. Section B. Natural, Exact, and Applied Sciences. 72(1), 23-28.

2. Zepa, J., Silamikele, L., Bulina, I., Lavrentjevs, V., Trapina, I., Klovins, J., Andersone, D., Lejnieks, A., Nikitina-Zake, L. 2018. CD 40 rs 4810485 T > G polymorphism and susceptibility to ankylosing spondylitis in the Latvian population. Genetics and Molecular Research. 17 (3), gmr18081. Available at: http://dx.doi.org/10.4238/gmr18081

Articles in local scientific journals

1. Zepa, J., Buliņa, I., Sikora, E., Ābelīte, S., Astiča, I., Zepa, L., N̦ikitina-Zaķe, L., Andersone, D., Lejnieks, A. 2013. Ankilozējošā spondilīta slimības aktivitātes saistība ar sirds un asinsvadu slimību attīstības riska faktoriem (Eng. Relationship of ankylosing spondylitis disease activity to risk factors for cardiovascular disease development). RSU Zinātniskie raksti. 52-59.

2. Buliņa, I., Zepa, J., Jaunalksne, I., Lavrentjevs, V., Astiča, I., Sikora, E., Ābelīte, S., Andersone, D. 2012. Seruma audzēja nekrotizējošā faktora alfa $\mathrm{TNF} \alpha$ un tā I tipa receptora TNF $\alpha \mathrm{R} 1$ izmaiņas anti-TNF alfa terapijas laikā ankilozējošā spondilīta pacientiem (Eng. Changes in serum tumour necrotising factor alpha $\mathrm{TNF} \alpha$ and its type I receptor TNF $\alpha \mathrm{R} 1$ during anti-TNF alpha therapy in ankylosing spondylitis patients). Latvijas Universitātes raksti. 788, 34-46.

Abstracts and participation in international congresses and conferences

1. Zepa, J., Bulina, I., Nikitina-Zake L., Klovins J., Jurka A., Tretjakovs P., Lejnieks A., Andersone D. the $33^{\text {rd }}$ European Workshop for Rheumatology Research: Lack of Association of Serum Interleukin-17 and Interleukin-23 Levels with Disease Activity in Patients with Ankylosing Spondylitis in Latvia. 28.02.2013-02.03.2013 Prague, Czech Republic. Ann Rheum Dis. 72 (Suppl 1), A78.

2. Zepa, J., Bulina I., Lavrentjevs, V., Kadike, S., Nikitina-Zake, L., Lejnieks, A., Andersone, D. the $34^{\text {th }}$ European Workshop for Rheumatology Research: Uveitis is not associated with the cardiovascular risk factors in patients with ankylosing spondylitis. 20.02.2014-22.02.2014 Lisbon, Portugal. Ann Rheum Dis. 73, A38-A39.

3. Zepa, J., Zepa., L, Bulina, I., Sarbantovica, A., Lavrentjevs, V., Sikora, E., Lejnieks, A., Andersone, D., Klovins, J., Nikitina-Zake, L. the $35^{\text {th }}$ Scandinavian Congress of Rheumatology: The Use of the mSASSS Method by 
Different Specialists. 20.09.2014-23.09.2014 Stockholm, Sweden. Scand J Rheumatol. 43(Suppl 127), 71.

4. Zepa, J., Zepa, L., Bulina, I., Sarbantovica, A., Lavrentjevs, V., Sikora, E., Lejnieks, A., Andersone, D., Klovins, J., Nikitina-Zake, L. the $35^{\text {th }}$ Scandinavian Congress of Rheumatology: A Number of Autoimmunity-related Gene Polymorphisms are not Associated with Ankylosing Spondylitis in Latvian Population. 20.09.2014-23.09.2014 Stockholm, Sweden. Scand J Rheumatol. 43(Suppl 127), 65-66.

5. Zepa, J., Zepa, L., Bulina, I., Sarbantovica, A., Lavrentjevs, V., Sikora, E., J.Arajs, J., Lejnieks, A., Andersone, D., Klovins, J., Nikitina-Zake, L. MYRACE: Young Rheumatologist Forums: Association of PTPN22 rs2476601 polymorphism and TGFB1 rs 1800470 with ankylosing sondylitis in Latvian population. 26.09.2013-28.09.2013 Bad Wiesse, Germany.

6. Zepa, J., Bulina, I., Lavrentjevs, V., Zepa, L., Priedite, I., Nikitina-Zake, L., Lejnieks, A., Andersone, D. the $9^{\text {th }}$ International Congress on Spondyloarthropathies: Impact of uveitis on characteristics of patients with ankylosing spondylitis. 23.10.2014-25.10.2014 Gent, Belgium.

Abstracts and participation in local conferences

1. Zepa, J., Buliṇa, I., Sikora, E., Ābelīte, S., Astiča, I., Zepa, L., N̦ikitina-Zaķe, L., Andersone, D., Lejnieks, A. RSU 2013. gada Zinātniskā konference. Stenda referāts: Ankilozējošā spondilīta slimības aktivitātes saistība ar sirds un asinsvadu slimību attīstības riska faktoriem (Eng. Relationship of ankylosing spondylitis disease activity to risk factors for cardiovascular disease development).

2. Zepa, J., Buliṇa, I., Kadik̦e, S., Priedīte, I., Lavrentjevs, V., Zepa, L., N̦ikitinaZaḳe, L., Lejnieks, A., Andersone, D. LU 2014. gada Zinātniskā konference. Mutiskais referāts: Mugurkaula rentgenolog̣isko izmaiṇu saistība ar ķermeņa masas indeksu un vēdera apkārtmēru pacientiem ar ankilozējošo spondilìtu (Eng. Relationship of spinal radiographic changes to body mass index and abdominal circumference in patients with ankylosing spondylitis).

Other articles in international scientific journals

1. Sivera, F., Ramiro, S., Cikes, N., ...., Zepa, J., ....., et al. 2015. Differences and similarities in rheumatology specialty training programmes across European countries. Ann Rheum Dis. 74(6), 1183-1187. Available at: doi:10.1136/annrheumdis-2014-206791 (member of the Working Group)

2. Sivera, F., Ramiro, S., Cikes, N., ...., Zepa, J., ....., et al. 2016. Rheumatology training experience across Europe: analysis of core competences. Arthritis Res Ther. 18(1),213. Available at: doi:10.1186/s13075-016-1114-y (member of the Working Group)

3. Beyer, C., Ramiro, S., Sivera, F., ...., Zepa, J., ....., et al. 2016. Educational needs and preferences of young European clinicians and physician researchers working in the field of rheumatology. RMD Open. 2(2), e000240. Available at: doi:10.1136/rmdopen-2015-000240 (collaborator) 


\section{Acknowledgements}

In medicine, it is not possible to do research alone, it is always a team effort.

I would like to express my deepest gratitude for moral support and professional help to: the supervisors Dr. habil. med. Professor Daina Andersone and Dr. med. Professor Aivars Lejnieks, the scientific advisor of the Doctoral Thesis Dr. med. Liene Nikitina-Zake, the director of the Latvian Biomedical Research and Study Centre Dr. med. Professor Janis Klovins and biologist Laila Silamikele, consultant in statistical issues $D r$. med. Ilva Trapina, my colleague and friend rheumatologist Inita Bulina, my teacher rheumatologist Vladimir Lavrentjev, radiologist Ilze Priedite, radiologist Helmuts Kidikas, laboratory assisstant Iveta Marks, nurses Ludmila Isajeva and Anzela Kirjanova, colleagues of the Rheumatology Centre and the Diagnostic Radiology Institute of Pauls Stradins Hospital.

I express my gratitude to the patients and control group for the agreement to participate in the study and opportunity to expand the knowledge in the field of rheumatology.

Sincere thanks to the Dean of Doctoral Studies Dr. med. Professor Sandra Lejniece, research process organizer $\mathrm{Dr}$. med. Irena Rogovska, promotions coordinator Laura Stepanova and the staff of the Doctoral Studies for support and high demands in the performance of the Thesis.

I express my gratitude to my Latvian language teacher Dr. paed. Beatrise Garjane and my family friends Evija and Andris Tare for their moral support and help.

Many sincere thanks to my family - husband Armands and daughter Paula Amanda, my parents, grandparents and my husband's grandfather Dr. habil. med. Professor Janis Baltkajs for their understanding, support and endurance throughout the process of this study and my doctor's career. 